\title{
Dichloromethane Crude Extract of Gymnanthemum extensum Combined with Low Piperine Fractional Piper nigrum Extract Induces Apoptosis on Human Breast Cancer Cells
}

\author{
M. FAISAL, S. MAUNGCHANBUREE, S. DOKDUANG, T. RATTANBUREE, A. TEDASEN ${ }^{1}$ AND P. GRAIDIST2*
}

Department of Biomedical Sciences and Biomedical Engineering, Faculty of Medicine, Prince of Songkla University, Songkhla, 90110, ${ }^{1}$ Medical Technology Program, School of Allied Health Sciences, Walailak University, Nakhonsithammarat, 80161, ${ }^{2}$ The Excellence Research Laboratory of Cancer Molecular Biology, Prince of Songkla University, Songkhla, 90110, Thailand

Faisal et al.: Gymnanthemum extensum Combined with Piper nigrum Induces Apoptosis

\begin{abstract}
This study aims to investigate the cytotoxicity of Andrographis paniculata, Ziziphus spina-christi and Gymnanthemum extensum crude extracts and their combination with low piperine fractional Piper nigrum extract. All plants were extracted with water and five organic solvents (methanol, ethanol, dichloromethane, ethyl acetate and hexane). Cytotoxicity was assessed by 3-(4,5-dimethylthiazol-2-yl)2,5-diphenyl tetrazolium bromide assay on three cancer types (breast, colorectal and ovarian cancers) and two non-cancerous cells. The combination among extracts with low piperine fractional Piper nigrum extract was separately conducted in several tests including cytotoxicity, apoptosis and multi caspase activity. We found that, the dichloromethane crude extract of Andrographis paniculata, Ziziphus spinachristi and Gymnanthemum extensum exhibited the strongest cytotoxicity on colorectal cancer cells $\mathrm{SW}$-620 $\left(7.49 \pm 0.04 \mu \mathrm{g} \mathrm{ml}^{-1}\right)$, breast cancer cells Michigan Cancer Foundation-7 (13.35 $\pm 0.30 \mu \mathrm{g}$. $\left.\mathrm{ml}^{-1}\right)$ and ovarian cancer cells A2780 (15.58 $\left.\pm 1.81 \mu \mathrm{g} \mathrm{ml}^{-1}\right)$, respectively. Gas chromatography mass spectrometry study of dichloromethane crude extract of Andrographis paniculata, Ziziphus spina-christi and Gymnanthemum extensum identified major compounds including 1-heptatriacotanol $(60.29 \%)$ and palmitic acid (26.92\% for dichloromethane crude extract of Ziziphus spina-christi and $\mathbf{2 1 . 4 0} \%$ for dichloromethane crude extract of Gymnanthemum extensum), respectively. The combination of dichloromethane crude extract of Ziziphus spina-christi and low piperine fractional Piper nigrum extract at ratio $\mathrm{IC}_{50}: 0.5 \mathrm{IC}_{50}$ showed a moderate synergistic effect on Michigan Cancer Foundation-7 cells. Interestingly, the mixture of dichloromethane crude extract of Gymnanthemum extensum with low piperine fractional Piper nigrum extract at ratio $\mathrm{IC}_{50}: \mathrm{IC}_{50}, 0.5 \mathrm{IC}_{50}: \mathrm{IC}_{50}$ and $\mathrm{IC}_{50}: 0.5 \mathrm{IC}_{50}$ exhibited a synergistic effect on Michigan Cancer Foundation-7 cells. Moreover, combination of dichloromethane crude extract of Gymnanthemum extensum with low piperine fractional Piper nigrum extract induced the apoptosis and multi caspase activity in a time dependent manner. In conclusion, dichloromethane crude extract of Andrographis paniculata, Ziziphus spina-christi and Gymnanthemum extensum displayed potent anticancer activities and the combination of dichloromethane crude extract of Gymnanthemum extensum with low piperine fractional Piper nigrum extract can be a promising regimen for an alternative cancer treatment.
\end{abstract}

Key words: Apoptosis, combination, dichloromethane, Gymnanthemum extensum, Piper nigrum

The Global Cancer Observatory (GLOBOCAN) estimated more than 9 million death cases worldwide owing to cancer. Predictably, it would threaten people worldwide as 17 million cancer deaths per year in $2030^{[1]}$. Breast and colorectal cancer are the top three in death rates worldwide ${ }^{[2]}$. Moreover, ovarian cancer is the deadliest cancer type besides breast and colorectal cancers and causes over $50 \%$ of the death rate ${ }^{[3]}$. Now

*Address for correspondence E-mail: gpotchan@medicine.psu.ac.th a days, several therapies to remedy cancers have been harnessed by clinicians such as surgery, radiotherapy and chemotherapy. Indeed, chemotherapy has been This is an open access article distributed under the terms of the Creative
Commons Attribution-NonCommercial-ShareAlike 3.0 License, which
allows others to remix, tweak, and build upon the work non-commercially,
as long as the author is credited and the new creations are licensed under
the identical terms

Accepted 17 March 2021 Revised 04 January 2021 Received 23 October 2020 Indian J Pharm Sci 2021;83(2):247-260 
acknowledged as the most commonly used therapy. Otherwise, chemotherapy somehow might lead to being ineffective therapy due to drug resistance and cancer recurrence ${ }^{[4]}$.

To date, over 3000 plant species have been revealed their potency as an anticancer agent ${ }^{[5]}$. Andrographis paniculata (A. paniculata) (Acanthaceae) is a shrub plant grown annually and distributed to tropical and subtropical Asia and also Southeast Asia ${ }^{[6]}$. Ziziphus spina-christi (Z. spina-christi) (Rhamnaceae) is an endemic plant of the middle east and distributed from Saharan Oases to West Africa ${ }^{[7]}$. Gymnanthemum extensum (G. extensum) (Asteraceae) is a bitter leaf tree distributed to Northeastern Thailand ${ }^{[8]}$. Previously, $A$. paniculata, Z. spina-christi and G. extensum leaves showed high cytotoxicity on several cancer cells, indicated by half-maximal inhibitory concentration $\left(\mathrm{IC}_{50}\right)$ lower than $20 \mu \mathrm{g} / \mathrm{ml}$.

The methanolic crude extract of $A$. paniculata leaves exhibited a strong cytotoxicity effect on nasopharynx (KB) and leukemic (P388) cells ${ }^{[9]}$ and colorectal cancer cells ${ }^{[10]}$. In addition, ethanolic crude extract of A. paniculata leaves also showed a high cytotoxicity effect on leukemic cells (HL-60) ${ }^{[11]}$. Ethyl acetate crude extract of $A$. paniculata leaves inhibited breast cancer (T-47D) and colorectal cancer (WiDr) cells ${ }^{[12]}$. Furthermore, Z. spina-christi leaves extracted in ethanol showed notable cytotoxicity on Michigan Cancer Foundation-7 (MCF-7) cells ${ }^{[13]}$. Methylene chloride crude extract of $G$. extensum showed high cytotoxicity on liver cancer (HepG2) cells ${ }^{[14]}$.

According to these previous findings, we then carried out a study to investigate the cytotoxicity of these three medicinal plants in a different polarity of organic solvents. The selection of five different solvents used in this present study was referred to their polarity which correlated with the dielectric constant ${ }^{[15]}$. The polarity of solvent from highest to lowest are methanol (32.7), ethanol (24.6), dichloromethane (9.08), ethyl acetate (6.02) and hexane (1.9), respectively ${ }^{[16]}$. In addition, consideration of selective anticancer agents of these three medicinal plants was conducted on three cancer types and two non-cancerous cells (Vero and L-929). These normal cells were isolated from normal kidney cells of green African monkey and murine normal fibroblast cells, respectively. Due to the genetic stability and non tumorigenicity feature of Vero and L-929 cells, they are suitable to use in cytotoxicity tests ${ }^{[17,18]}$.

Previously, we reported that low piperine fractional Piper nigrum (P. nigrum) extract (PFPE) exhibited the highest cytotoxicity compared to piperine and dichloromethane extract of $P$. nigrum ${ }^{[19]}$. This extract was able to inhibit various cancer cells including breast cancer (MCF-7, M.D. Anderson (MDA) Metastasis Breast cancer (MB)-468 and ZR-75-1) and cholangiocarcinoma (KKU-100, KKU-M213, KKU-M055 and human extrahepatic bile duct carcinoma cell line (TFK-1) ${ }^{[20]}$. Phytochemical compounds including kusunokinin and piperlongumine isolated from PFPE showed high cytotoxicity against breast cancer (MCF-7 and MDA-MB-468) and colorectal cancer (SW-620). PFPE degraded the proteins in cancer progression including signal transducer and activator of transcription 3 (STAT-3), cyclooxygenase-2 (COX-2), nuclear factor-kappa B (NF-kB), Topoisomerase II, Cellular myelocytomatosis oncogene (c-myc), cyclin D1 and B-cell lymphoma 2 (Bcl-2)). Moreover, PFPE contained pipericine, 2,4,14-eicosatrienamide, retrofractamide-a and piperanine showed cytoprotective on L-929 cells and hepatoprotective ${ }^{[20-22]}$. Furthermore, PFPE exhibited very low cytotoxicity against murine fibroblast cells (L-929 cells) ${ }^{[20]}$. Due to PFPE, showed high cytotoxicity on cancer cells and hepatoprotective activity, we here performed the combination of PFPE together with those three plant extracts to increase cytotoxicity which is higher than a single treatment.

A combination in cancer treatment has been recognized as an effective way to improve successful treatment by increasing the cytotoxicity ${ }^{[23]}$. The combination of $A$. paniculata with Silybum marianum showed a higher percentage of cell inhibition on breast (MCF7), ovarian (Human cervical tumor cell-SiHa) and liver (human liver cancer cell line-HepG2) cancer cells than each individual treatment ${ }^{[24]}$. Moreover, Z. spina-christi with termite shelter extract concentration at $300 \mu \mathrm{g} / \mathrm{ml}$ exhibited stronger cytotoxicity on cervical cells (Henrietta Lacks-HeLa) than individual treatment ${ }^{[25]}$. Thus, we hypothesized that A. paniculata, Z. spina-christi and G. extensum would have stronger cytotoxicity once we combined them with PFPE rather than a single treatment. In this report, we conducted the cytotoxicity test of different extracts of $A$. paniculata, Z. spina-christi and G. extensum leaves individually and their combination with PFPE on cancer cells. Phytocompounds were observed by gas chromatography-mass spectrometry (GC-MS) and the cytotoxicity of three medicinal plants alone and their combination with PFPE on cancer cells was measured by 3-(4,5-dimethylthiazol-2-yl)-2,5diphenyl tetrazolium bromide (MTT) assay. Finally, to approach further results whether the regimen could 
inhibit precisely cancer cells growth only, apoptosis and multi caspase analysis were performed by flow cytometry analysis.

\section{MATERIALS AND METHODS}

\section{Plant materials collection:}

Dried leaves of A. paniculata and dried fruits P. nigrum were harvested from Banten Province, Indonesia and Songkhla Province, Thailand, respectively. Both plant specimens were authenticated by Assistant Professor Dr. Supreeya Yuenyongsawad and deposited in the Herbarium of Southern Centre of Thai Traditional Medicine, Department of Pharmacognosy and Pharmaceutical Botany, Prince of Songkla University (PSU), Thailand as a voucher specimen number SKP 001011601 and SKP 146161401, respectively. Dried leaves of $Z$. spina-christi was harvested from East Java Province, Indonesia and taxonomically authenticated by Dr. Nurainas (Chief of ANDA Herbarium, Department of Biology, Andalas University) with letter No. 305/ K-ID/ANDA/IX/2018. Dried leaves of $G$. extensum were harvested from Phatthalung Province, Thailand and identified by Professor Dr. Suchada Sukrong and deposited as a voucher specimen (No. SS-PG-001) and kept at the Museum of Natural Medicine, Faculty of Pharmaceutical Science, Chulalongkorn University, Thailand.

\section{Chemicals and reagents:}

In extraction protocol, ethanol $\left(\mathrm{C}_{2} \mathrm{H}_{5} \mathrm{OH}\right)$, methanol $\left(\mathrm{CH}_{3} \mathrm{OH}\right)$, dichloromethane $\left(\mathrm{CH}_{2} \mathrm{Cl}_{2}\right)^{5}$, ethyl acetate $\left(\mathrm{C}_{4} \mathrm{H}_{8} \mathrm{O}_{2}\right)$ and acetone $\left(\mathrm{C}_{3} \mathrm{H}_{6} \mathrm{O}\right)$ was purchased from J. T. Baker ${ }^{\circledR}$ (Phillipsburg, NJ, USA). Hexane $\left(\mathrm{C}_{6} \mathrm{H}_{14}\right)$ was purchased from Reagent Chemical Industry (RCI) LabScan Ltd (Bangkok, Thailand). Furthermore, to make 1x phosphate buffered saline (PBS) for cell culture, the chemical substance such as sodium chloride $(\mathrm{NaCl})$ was purchased in Omnipur ${ }^{\circledR}$ (Idaho, ID, USA). Moreover, sodium phosphate dibasic anhydrous $\left(\mathrm{Na}_{2} \mathrm{HPO}_{4}\right)$, potassium chloride $(\mathrm{KCl})$, potassium phosphate $\left(\mathrm{KH}_{2} \mathrm{PO}_{4}\right)$ and dimethyl sulfoxide $\left(\mathrm{C}_{2} \mathrm{H}_{6} \mathrm{OS}\right)$ were purchased from Amresco ${ }^{\circledR}$ (Solon, OH, USA). In the cell culture study, the cell medium and supplements including Roswell Park Memorial Institute Medium (RPMI-1640) and Dulbecco's Modified Eagle Medium (DMEM) powder, L-Glutamine, Fetal Bovine Serum (FBS) and antibiotics (penicillin-streptomycin) were purchased from Gibco $^{\mathrm{TM}}$ (Massachusetts, USA). MTT assay and dimethyl sulfoxide $\left(\mathrm{C}_{2} \mathrm{H}_{6} \mathrm{OS}\right)$ were purchased from GibThai (Bangkok, Thailand) and Amresco ${ }^{\circledR}$, respectively. Apoptosis and multi caspase reagents were purchased from Becton, Dickinson (BD) Biosciences, Inc (San Jose, CA, USA).

\section{Maceration extraction:}

$3 \mathrm{~g}$ of pulverized dried leaves were soaked in $300 \mathrm{ml}$ of five types of organic solvents consists of methanol, ethanol, dichloromethane, ethyl acetate and hexane. Afterward, the mixture was filtered using Whatman Paper No. 1 filter paper. The filtrates were evaporated using a rotor evaporator at 40-45 , 1-3 mbar of vacuum pressure and $40 \mathrm{rpm}$ of rotation. Then, the crude extracts were stored at $-20^{\circ}$ until used. The stock solution was diluted with dimethyl sulfoxide (DMSO).

\section{Decoction extraction and lyophilization:}

$3 \mathrm{~g}$ of pulverized dried leaves were soaked in $300 \mathrm{ml}$ of boiled water within $10 \mathrm{~min}$. Next, the extracts were placed in room temperature. After the temperature of extracts was decreased, the extracts were lyophilized by the freeze-drying method as described by Seong and colleagues $^{[26]}$. Then, the freeze- dried extracts were kept at $-20^{\circ}$ until used. The stock solution was diluted with dimethyl sulfoxide (DMSO).

\section{Cell culture:}

Human breast adenocarcinoma MCF-7 and MDAMB-231, colorectal (HT-29 and SW-620) and ovarian (A2780 and SKOV-3) were used as cancerous representative cells. MCF-7 (American Type Culture Collection $\left(\right.$ ATCC $^{\circledR}$ ) HTB-22), MDA-MB-231 (ATCC ${ }^{\circledR}$ HTB-26), SKOV-3 (ATCC ${ }^{\circledR}$ HTB-77) and Vero (ATCC ${ }^{\circledR}$ CCL-81) cells were purchased from American Type Culture Collection (Manassas, Virginia, USA). A2780 cells were purchased from AddexBio (San Diego, California, USA). SW-620 cells were kindly donated by Dr. Surasak Sangkhathat, MD from Department of Surgery, Faculty of Medicine, Prince of Songkla University (PSU). Meanwhile, HT-29 cells were kindly given by Dr. Ruedeekorn Wiwattanapatapee from Department of Pharmaceutical Technology, Faculty of Pharmaceutical Sciences, PSU. L-929 cells were kindly provided by Dr. Jasadee Kaewsichan (Department of Pharmaceutical Chemistry, Faculty of Pharmaceutical Sciences, PSU). Vero, A2780 and SKOV-3 cells were cultured in RPMI-1640 culture medium. HT-29, SW620, MDA-MB-231 and L-929 cells were grown in DMEM. Both media (RPMI-1640 and DMEM) were supplemented with $10 \%$ fetal bovine serum and 
$1 \%$ of penicillin and streptomycin. All cultures were maintained at an incubation condition of $37^{\circ}$ in $5 \%$ carbon dioxide and at $95 \%$ relative humidity.

\section{Cytotoxicity of individual extract:}

To investigate the cytotoxicity in a single extract, an MTT colorimetric assay was conducted. Cells in the medium were seeded into 96-well plates (SDL Biosciences, Thailand). MCF-7, MDA-MB-231, SW620 and SKOV-3 cells were seeded at a density of $2 \times 10^{3}$ cells/well. Vero, L-929 and A2780 cells were seeded at a density of $1 \times 10^{3}$ cells/well and HT-29 cells were seeded at a density of $1.5 \times 10^{3}$ cells/well. All seeded cells were incubated within $24 \mathrm{~h}$ for adhering. The cell medium was mixed with extracts with different concentrations $(5,10,20,40$ and $80 \mu \mathrm{g} / \mathrm{ml})$ and applied to the cells within $72 \mathrm{~h}$. As a positive control, doxorubicin with different concentrations $(0.625,1.25,2.5,5$ and $10 \mu \mathrm{m})$ was applied to the respective wells. Furthermore, $0.5 \% \mathrm{v} / \mathrm{v}$ of DMSO (a final concentration) was added to the complete cell medium mentioned as a vehicle. A complete cell medium with cells was mentioned as a negative control. After $72 \mathrm{~h}$, the cell medium was changed by $100 \mu 1$ MTT for $30 \mathrm{~min}$ and then dissolved by $100 \mu 1$ of DMSO per well to accumulate the formazan salt. The colour formation was generated and observed using a microplate reader spectrophotometer (Spectra Max M5, Molecular Devices) at $570 \mathrm{~nm}$ and $650 \mathrm{~nm}$, then the $\mathrm{IC}_{50}$ values were calculated using the formula as previously described ${ }^{[19]}$. Refers to the National Cancer Institute (NCI), a plant extract is considered to possess in vitro activity with the $\mathrm{IC}_{50}$ value of $\leq 20 \mu \mathrm{g} / \mathrm{ml}^{[19]}$. The $\mathrm{IC}_{50}$ of the individual extract was used as the initial concentration of the combination study. The selective index (SI) was determined adapted by Sriwiriyajan and colleagues ${ }^{[27]}$ which divided the $\mathrm{IC}_{50}$ values of extracts of non-cancerous cells with the $\mathrm{IC}_{50}$ values of extracts on cancer cells.

\section{Gas Chromatography/Mass (GC/MS):}

Spectrometry

To confirm the presence of phytocompounds possessed of notable cytotoxicity, gas chromatography/mass spectrometry analysis was conducted using two analytical instruments, Gas chromatography Agilent 7890B and Agilent 5977A triple quadrupole mass spectrometer (Agilent Technologies Inc, USA). This protocol was performed as previously described ${ }^{[20]}$.

Cytotoxicity of combination extract: The present study was conducted to investigate the interaction of this combination exhibited synergism, additive, or antagonism in inhibiting cancer cells. The combination extract protocol was conducted by MTT colorimetric assay. This investigation was performed by four ratios including $\mathrm{IC}_{50}$ extract: $\mathrm{IC}_{50}$ PFPE; $0.5 \times \mathrm{IC}_{50}$ extract: $\mathrm{IC}_{50}$ PFPE; $\mathrm{IC}_{50}$ extract: $0.5 \times \mathrm{IC}_{50}$ PFPE and $0.5 \times \mathrm{IC}_{50}$ extract: $0.5 \times \mathrm{IC}_{50}$ PFPE. The combination treatment results were computerized by "CompuSyn" software to procure the combination index values ${ }^{[28]}$. Manually, the combination index (CI) values were calculated by the Chou-Talalay equation ${ }^{[29]}$.

The interaction of combination was indicated by CI, which estimated from dose effect data, both single and combined drug treatments. The synergism was identified from a CI value based on the criteria as followed: $\mathrm{CI}<0.1$ (synergism); 0.1-0.3 (strong synergism); 0.30.7 (synergism); 0.7-0.85 (moderate synergism); 0.850.9 (slight synergism); 0.90-1.10 (nearly additive); 1.10-1.45 (slight antagonism); 1.45-3.3 (antagonism); 3.3-10 (strong antagonism) and $>10$ (very strong antagonism $)^{[30]}$.

\section{Apoptosis assay:}

In the present study, apoptotic and necrotic cells were observed using an annexin V-fluorescein isothiocyanate (FITC) and propidium iodide (PI) detection kit (Catalog No. MCH100105, Merck Millipore), following the manufacturer's instruction. Briefly, MCF7 cells $\left(2 \times 10^{5}\right.$ cells/well $)$ were seeded in 12 well plates. Afterward, the cells were incubated with the combination of dichloromethane crude extract of Gymnanthemum extensum DEGE with PFPE at ratio $\mathrm{IC}_{50}: \mathrm{IC}_{50}$ at various times $(0,24,48$ and $72 \mathrm{~h})$. Treated cells were harvested and cell pellets were incubated in $100 \mu 1$ of Muse ${ }^{\circledR}$ FITC-Annexin V apoptosis staining kit and $100 \mu 1$ of propidium iodide for $30 \mathrm{~min}$. The signal of fluorescent was observed by flow cytometry using Muse $^{\circledR}$ Cell Analyzer (Merck Millipore, Germany).

\section{Multi caspase assay:}

The observation of multi caspase activity was performed by Muse $^{\circledR}$ multi caspase assay kit (Catalog No. MCH100109, Merck Millipore), following the manufacturer's instruction. The MCF7 cells were seeded into 12 well plates at a density of $2 \times 10^{5}$ cells/well. Afterward, the cells were treated by the combination of DEGE and PFPE (ratio $\mathrm{IC}_{50}: \mathrm{IC}_{50}$ ) at various times $(0,24,48$ and $72 \mathrm{~h})$. The cells were harvested and cell pellets were resuspended in $5 \mu \mathrm{l}$ of 
Muse $^{\circledR}$ Multi caspase assay for 30 min followed by $150 \mu 1$ of 7-Aminoactinomycin D (7-AAD) within $15 \mathrm{~min}$. The fluorescent marks of multi caspase and 7-AAD were completely identified by the Muse ${ }^{\circledR}$ Cell Analyzer (Merck Millipore, Germany).

\section{Statistical analysis:}

All experiments were done in triplicate of each experiment and the data was calculated from three independent experiments. The $\mathrm{IC}_{50}$ values were expressed as the mean \pm standard deviation (SD). The percentages of apoptosis and multi caspase were presented as an average and SD. All graphs were created by GraphPad Prism 8. The apoptosis and multi caspase data were statistically analyzed by the Student t-test to compare among the treated group and control group using Microsoft excel software. $\mathrm{p}<0.05$ was considered statistically significant.

\section{RESULTS AND DISCUSSION}

Cancer have been a health concern caused by free radicals and carcinogens, which have been naturally and artificially established to harm Deoxyribonucleic acid (DNA) $)^{[31]}$. Until now, many attempts for precise and effective cancer anticancer therapy were investigated and recognized as complementary alternative medicine (CAM), due to the fear of society against synthetic drugs detrimental effects. One of interesting CAM is to use plant extracts as an anticancer therapy. A. paniculata leaf was reported to possess of anticancer activity.

According to results in Table 1, we selected dichloromethane extract of $A$. paniculata (DEAP) for the next experiment due to its cytotoxicity on both HT-29 $\left(8.93 \pm 0.52 \mu \mathrm{g} \mathrm{ml}^{-1}\right)$ and SW-620 cells $\left(7.49 \pm 0.04 \mu \mathrm{g} \cdot \mathrm{ml}^{-1}\right)$. Even though methanolic extract of A. paniculata (MEAP) also showed strong cytotoxicity on SKOV-3 cells $\left(7.60 \pm 0.72 \mu \mathrm{g} \mathrm{ml}^{-1}\right)$, we rather considered the dichloromethane extract as the extract which can affect the two cell types, than methanolic one where only one cell type affected. In this present study, we also used high polar solvent such as methanol and ethanol. Empirically, organic solvents with higher

TABLE 1: CYTOTOXICITY OF A. paniculata LEAVES PREPARED IN SIX SOLVENTS AGAINST DIFFERENT TYPE OF CANCER CELLS

\begin{tabular}{|c|c|c|c|c|c|c|c|}
\hline \multirow{2}{*}{ Cell Line } & \multicolumn{7}{|c|}{$I_{50}$ value $(\mu \mathrm{g} / \mathrm{ml})(\mu \mathrm{M})^{\mathrm{a}}$} \\
\hline & $\begin{array}{c}\operatorname{FEAP}\left(\mathrm{SI}_{\text {Vero }},\right. \\
\left.\mathrm{SI}_{\mathrm{L}-929}\right)\end{array}$ & $\begin{array}{l}\operatorname{MEAP}\left(\mathrm{SI}_{\text {Vero }},\right. \\
\left.\mathrm{SI}_{\mathrm{L}-929}\right)\end{array}$ & $\begin{array}{c}\operatorname{EEAP}\left(\mathrm{SI}_{\text {Vero }},\right. \\
\left.\mathrm{SI}_{\mathrm{L}-929}\right)\end{array}$ & $\begin{array}{c}\operatorname{DEAP}\left(\mathrm{SI}_{\text {Vero }},\right. \\
\left.\mathrm{SI}_{\mathrm{L}-929}\right)\end{array}$ & $\begin{array}{c}\text { EAAP (SI }{ }_{\text {Vero }}, \\
\left.\text { SI }_{L-929}\right)\end{array}$ & $\begin{array}{l}\operatorname{HEAP}\left(\mathrm{SI}_{\text {Vero }},\right. \\
\left.\mathrm{SI}_{\mathrm{L}-929}\right)\end{array}$ & $\begin{array}{c}\operatorname{DOX}\left(\mathrm{SI}_{\text {Vero }},\right. \\
\left.\mathrm{SI}_{\mathrm{L}-929}\right)\end{array}$ \\
\hline \multicolumn{8}{|c|}{ Breast cancer } \\
\hline MCF-7 & $\begin{array}{l}\text { Not inhibited } \\
\quad(N D, N D)\end{array}$ & $\begin{array}{c}14.97 \pm 1.56 \\
(1.22,0.72)\end{array}$ & $\begin{array}{c}18.44 \pm 1.71 \\
(0.77,2.43)\end{array}$ & $\begin{array}{c}26.77 \pm 2.18 \\
(0.53,0.93)\end{array}$ & $\begin{array}{l}21.64 \pm 0.93 \\
(0.69,0.95)\end{array}$ & $\begin{array}{c}47.46 \pm 0.93 \text { (ND, } \\
N D)\end{array}$ & $\begin{array}{c}1.15 \pm 0.07(6.84 \\
1.38)\end{array}$ \\
\hline MDA- MB-231 & $\begin{array}{l}\text { Not inhibited } \\
\quad(N D, N D)\end{array}$ & $\begin{array}{c}12.54 \pm 1.38 \\
(1.46,0.86)\end{array}$ & $\begin{array}{l}21.49 \pm 0.21 \\
(0.66,2.08)\end{array}$ & $\begin{array}{c}24.03 \pm 0.40 \\
(0.59,1.04)\end{array}$ & $\begin{array}{c}19.06 \pm 1.15 \\
(0.79,1.07)\end{array}$ & $\begin{array}{l}\text { Not inhibited } \\
(N D, N D)\end{array}$ & $\begin{array}{c}1.57 \pm 0.23(5.02 \\
1.01)\end{array}$ \\
\hline \multicolumn{8}{|c|}{ Colorectal cancer } \\
\hline HT-29 & $\begin{array}{l}\text { Not inhibited } \\
\quad(N D, N D)\end{array}$ & $\begin{array}{c}13.77 \pm 1.61 \\
(1.33,0.78)\end{array}$ & $\begin{array}{c}12.45 \pm 0.05 \\
(1.13,3.59)\end{array}$ & $\begin{array}{c}8.93 \pm 0.52 \\
(1.58,2.80)\end{array}$ & $\begin{array}{l}13.17 \pm 0.52 \\
(1.14,1.56)\end{array}$ & $\begin{array}{l}\text { Not inhibited } \\
(N D, N D)\end{array}$ & $\begin{array}{c}2.53 \pm 0.56(3.11 \\
0.63)\end{array}$ \\
\hline SW-620 & $\begin{array}{l}\text { Not inhibited } \\
\quad(N D, N D)\end{array}$ & $\begin{array}{c}12.39 \pm 1.61 \\
(1.47,0.87)\end{array}$ & $\begin{array}{c}12.08 \pm 0.82 \\
(1.17,3.70)\end{array}$ & $\begin{array}{c}7.49 \pm 0.04 \\
(1.89,3.34)\end{array}$ & $\begin{array}{c}10.31 \pm 0.32 \\
(1.46,1.99)\end{array}$ & $\begin{array}{c}39.40 \pm 0.42 \text { (ND) } \\
\text { ND) }\end{array}$ & 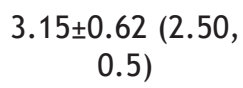 \\
\hline \multicolumn{8}{|c|}{ Ovarian cancer } \\
\hline A2780 & $\begin{array}{l}\text { Not inhibited } \\
\quad(N D, N D)\end{array}$ & $\begin{array}{c}15.29 \pm 0.68 \\
(1.19,0.70)\end{array}$ & $\begin{array}{c}20.51 \pm 1.60 \\
(0.69,2.18)\end{array}$ & $\begin{array}{c}10.98 \pm 0.48 \\
(1.29,2.28)\end{array}$ & $\begin{array}{c}13.53 \pm 1.28 \\
(1.11,1.51)\end{array}$ & $34.27 \pm 2.31$ & $\begin{array}{c}2.33 \pm 0.18(3.38 \\
0.68)\end{array}$ \\
\hline SKOV-3 & $\begin{array}{l}\text { Not inhibited } \\
\quad(N D, N D)\end{array}$ & $\begin{array}{c}7.60 \pm 0.72 \\
(2.40,1.41)\end{array}$ & $\begin{array}{c}30.6 \pm 0.93 \\
(0.46,1.46)\end{array}$ & $\begin{array}{c}19.34 \pm 0.15 \\
(0.74,1.29)\end{array}$ & $\begin{array}{c}17.23 \pm 1.28 \\
(0.87,1.19)\end{array}$ & $\begin{array}{l}\text { Not inhibited } \\
(N D, N D)\end{array}$ & $\begin{array}{c}1.64 \pm 0.19(4.80 \\
0.97)\end{array}$ \\
\hline \multicolumn{8}{|c|}{ Non-cancerous } \\
\hline Vero & Not inhibited & $18.27 \pm 1.22$ & $14.11 \pm 1.59$ & $14.14 \pm 0.29$ & $15.02 \pm 0.94$ & Not inhibited & $7.88 \pm 0.43$ \\
\hline L-929 & Not inhibited & $10.75 \pm 0.27$ & $44.74 \pm 2.44$ & $25.02 \pm 1.07$ & $20.48 \pm 1.34$ & Not inhibited & $1.59 \pm 0.18$ \\
\hline
\end{tabular}

Data represented mean $\pm \mathrm{SD}$ from three independent experiments. $\mathrm{SI}_{\mathrm{Vero}}$ or $\mathrm{SI}_{\mathrm{L}-929}$ cells are selectivity index, calculated by dividing $\mathrm{IC}_{50}$ of Vero or L-929 with $I C_{50}$ cancer cells. ${ }^{a}$ Doxorubicin concentration was in a unit of $\mu M$, Not inhibited: $I C_{50}$ not observed at the maximum concentration at $80 \mu \mathrm{g} / \mathrm{ml}$, ND: not determined, FEAP: freeze-dried extract of $A$. paniculata, MEAP: methanol extract of $A$. paniculata, EEAP: ethanol extract of $A$. paniculata, DEAP: dichloromethane extract of $A$. paniculata, EAAP: ethyl acetate extract of $A$. paniculata, HEAP: hexane extract of $A$. paniculata 
dielectric constant prefer to dissolve and interact with polar compounds. Correlating with the extracted phytocompounds, methanol is capable to dissolve antioxidant compounds such as phenol and polyphenol which is proved by the total antioxidant contents ${ }^{[32]}$. This information led to an implication that the antioxidant may play a role in cytotoxicity from MEAP.

Previously, the dichloromethane extract of A. paniculata leaves showed considerable cytotoxicity on HT-29 cells $^{[33]}$. Another promising extract, dichloromethane extract of Z. spina-christi leaf (DEZSC), also showed notable cytotoxicity towards breast and ovarian cancer cells, MCF-7 cells $\left(13.35 \pm 0.30 \mu \mathrm{g} . \mathrm{ml}^{-1}\right)$ and A2780 cells $\left(14.64 \pm 1.51 \mu \mathrm{g} . \mathrm{ml}^{-1}\right)$, shown in Table 2. Apart from the dichloromethane extract, a previous investigation by Farmani and colleagues revealed that the methanol extract of $Z$. spina-christi exhibited notable cytotoxicity on MCF-7 cells ${ }^{[13]}$. In addition, an endemic plant of Northeastern Thailand, G. extensum, extracted by dichloromethane (abbreviated as DEGE) demonstrated strong cytotoxicity against MCF-7 (15.58 \pm 1.81 $\left.\mu \mathrm{g} . \mathrm{ml}^{-1}\right)$ and A2780 cells $\left(10.08 \pm 0.04 \mu \mathrm{g} . \mathrm{ml}^{-1}\right)$ (Table 3). The dichloromethane extract of Vernonia extensa (synonym of $G$. extensum) was additionally reported for strong cytotoxicity on HepG2 (liver carcinoma cells), HuCCA-1 (cholangiocarcinoma cells), A549 (lung cancer cells) and MOLT-3 (leukemic

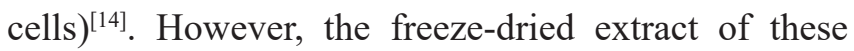
three plants has no cytotoxic effect on tested cells, which could bencaused by freeze-drying process which damaged the phytocompounds structure and finally led to the losing activity of compounds after the

TABLE 2: CYTOTOXICITY OF Z. spina-christi LEAVES PREPARED IN SIX SOLVENTS AGAINST DIFFERENT TYPE OF CANCER CELLS

\begin{tabular}{|c|c|c|c|c|c|c|c|}
\hline \multirow[t]{2}{*}{ Cell Line } & \multicolumn{7}{|c|}{$\mathrm{IC}_{50}$ value $(\mu \mathrm{g} / \mathrm{ml})(\mu \mathrm{M})^{\mathrm{a}}$} \\
\hline & $\begin{array}{l}\text { FEZSC } \\
\left(\mathrm{SI}_{\text {Vero' }},\right. \\
\left.\mathrm{SI}_{\mathrm{L}-929}\right) \\
\end{array}$ & $\begin{array}{c}\text { MEZSC (SI } \\
\left.\mathrm{SI}_{\mathrm{L}-929}\right)\end{array}$ & $\begin{array}{c}\text { EEZSC (SI }{ }_{\text {vero' }} \\
\left.\mathrm{SI}_{\mathrm{L}-929}\right)\end{array}$ & $\begin{array}{c}\text { DEZSC (SI } \\
\left.\mathrm{SI}_{\mathrm{L}-929}\right)\end{array}$ & $\begin{array}{c}\text { EAZSC (SI } \\
\left.\text { SI }_{\text {Lero } 929}\right)\end{array}$ & $\begin{array}{l}\text { HEZSC (SI }{ }_{\text {Vero }}, \\
\left.\mathrm{SI}_{\mathrm{L}-929}\right)\end{array}$ & $\begin{array}{c}\operatorname{DOX}\left(\mathrm{SI} \mathrm{Vero}_{\text {Ver }}\right. \\
\left.\mathrm{SI}_{\mathrm{L}-929}\right)\end{array}$ \\
\hline \multicolumn{8}{|c|}{ Breast cancer } \\
\hline MCF-7 & $\begin{array}{c}\text { Not } \\
\text { inhibited } \\
(\mathrm{ND}, \mathrm{ND})\end{array}$ & $107.19 \pm 1.64$ & $\begin{array}{l}\text { Not inhibited } \\
\quad(N D, N D)\end{array}$ & $\begin{array}{l}13.35 \pm 0.30 \\
(1.58,3.52)\end{array}$ & $\begin{array}{l}57.63 \pm 0.25 \\
(0.92, N D)\end{array}$ & $\begin{array}{l}\text { Not inhibited } \\
\quad(N D, N D)\end{array}$ & $\begin{array}{c}1.15 \pm 0.07(6.84 \\
1.38)\end{array}$ \\
\hline $\begin{array}{l}\text { MDA- } \\
\text { MB-231 }\end{array}$ & $\begin{array}{c}\text { Not } \\
\text { inhibited } \\
(N D, N D)\end{array}$ & $\begin{array}{c}80.83 \pm 1.65 \\
(N D, N D)\end{array}$ & $\begin{array}{l}\text { Not inhibited } \\
\quad(N D, N D)\end{array}$ & $\begin{array}{l}38.12 \pm 0.23 \\
(0.55,1.23)\end{array}$ & $\begin{array}{c}55.13 \pm 0.44 \\
(0.96, N D)\end{array}$ & $\begin{array}{l}\text { Not inhibited } \\
\quad(N D, N D)\end{array}$ & $\begin{array}{c}1.57 \pm 0.23(5.02 \\
1.01)\end{array}$ \\
\hline \multicolumn{8}{|c|}{ Colorectal cancer } \\
\hline HT-29 & $\begin{array}{c}\text { Not } \\
\text { inhibited } \\
(\mathrm{ND}, \mathrm{ND})\end{array}$ & $\begin{array}{c}39.01 \pm 2.65 \\
(N D, N D)\end{array}$ & $\begin{array}{c}82.35 \pm 11.96 \\
(N D, N D)\end{array}$ & $\begin{array}{l}17.02 \pm 0.69 \\
(1.24,2.76)\end{array}$ & $\begin{array}{c}96.46 \pm 12.08 \\
(0.55, N D)\end{array}$ & $\begin{array}{l}\text { Not inhibited } \\
\quad(N D, N D)\end{array}$ & $\begin{array}{c}2.53 \pm 0.56(3.11 \\
0.63)\end{array}$ \\
\hline SW-620 & $\begin{array}{c}\text { Not } \\
\text { inhibited } \\
(\mathrm{ND}, \mathrm{ND})\end{array}$ & $\begin{array}{c}77.91 \pm 2.04 \\
(N D, N D)\end{array}$ & $\begin{array}{c}40.73 \pm 0.73 \\
(N D, N D)\end{array}$ & $\begin{array}{c}23.2 \pm 1.08(0.91 \\
2.03)\end{array}$ & $\begin{array}{c}39.67 \pm 2.85 \\
(1.34, N D)\end{array}$ & $\begin{array}{l}\text { Not inhibited } \\
\quad(N D, N D)\end{array}$ & $\begin{array}{c}3.15 \pm 0.62(2.50 \\
0.5)\end{array}$ \\
\hline \multicolumn{8}{|c|}{ Ovarian cancer } \\
\hline A2780 & $\begin{array}{c}\text { Not } \\
\text { inhibited } \\
(\mathrm{ND}, \mathrm{ND})\end{array}$ & $\begin{array}{c}18.54 \pm 2.33 \\
(N D, N D)\end{array}$ & $\begin{array}{c}36.23 \pm 1.27 \\
(N D, N D)\end{array}$ & $\begin{array}{c}14.64 \pm 1.51 \\
(1.44,3.21)\end{array}$ & $\begin{array}{c}53.86 \pm 2.46 \\
(0.99, N D)\end{array}$ & $\begin{array}{l}\text { Not inhibited } \\
\text { (ND, ND) }\end{array}$ & $\begin{array}{c}2.33 \pm 0.18(3.38 \\
0.68)\end{array}$ \\
\hline SKOV-3 & $\begin{array}{c}\text { Not } \\
\text { inhibited } \\
(N D, N D)\end{array}$ & $\begin{array}{l}\text { Not inhibited } \\
\quad(N D, N D)\end{array}$ & $\begin{array}{l}\text { Not inhibited } \\
\quad(N D, N D)\end{array}$ & $\begin{array}{l}44.45 \pm 0.79 \\
(0.47,1.06)\end{array}$ & $\begin{array}{l}\text { Not inhibited } \\
\quad(N D, N D)\end{array}$ & $\begin{array}{l}\text { Not inhibited } \\
\quad(N D, N D)\end{array}$ & $\begin{array}{c}1.64 \pm 0.19(4.80 \\
0.97)\end{array}$ \\
\hline \multicolumn{8}{|c|}{ Non-cancerous } \\
\hline Vero & $\begin{array}{c}\text { Not } \\
\text { inhibited }\end{array}$ & Not inhibited & Not inhibited & $21.05 \pm 0.18$ & $53.11 \pm 0.16$ & Not inhibited & $7.88 \pm 0.43$ \\
\hline L-929 & $\begin{array}{c}\text { Not } \\
\text { inhibited }\end{array}$ & Not inhibited & Not inhibited & $47.03 \pm 2.91$ & Not inhibited & Not inhibited & $1.59 \pm 0.18$ \\
\hline
\end{tabular}

Data represented mean $\pm \mathrm{SD}$ from three independent experiments. $\mathrm{SI}_{\text {Vero }}$ or $\mathrm{SI}_{\mathrm{L}-929}$ cells are selectivity index, calculated by dividing $\mathrm{IC}_{50}$ of

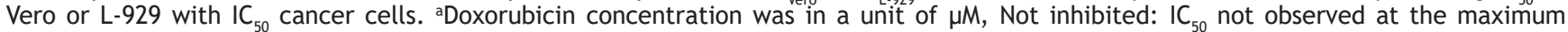
concentration at $80 \mu \mathrm{g} / \mathrm{ml}$, ND: not determined, FEZSC: freeze-dried extract of Z. spina-christi, MEZSC: methanol extract of Z. spinachristi, EEZSC: ethanol extract of Z. spina-christi, DEZSC: dichloromethane extract of Z. spina-christi, EAZSC: ethyl acetate extract of Z. spina-christi, HEZSC: hexane extract of Z. spina-christi 
rehydration process ${ }^{[34]}$. In this study, Vero and L-929 cells were used for determining SI score by dividing $\mathrm{IC}_{50}$ of non-cancerous cell lines with $\mathrm{IC}_{50}$ of cancer cell lines. Our results demonstrated SIL929 values of DEAP and DEZSC more than 2 on HT-29, SW-620, A2780 and MCF-7 cells. According to Koch and colleagues, SI score of less than 2.0 indicates toxicity to noncancerous cell lines ${ }^{[35]}$. However, several extracts could not be calculated for the cytotoxicity at the maximum concentration because the extract did not show an inhibitory effect on cancer cells. These results were noted as "Not determined (ND)", shown in Tables 1-3.

Due to strong cytotoxicity exhibited by DEAP, DEZSC and DEGE, we decided to perform a phytochemical characterization. Two major DEAP compounds were 1-heptatriacotanol $(60.29 \%$, alcohol $)$ and androsta-

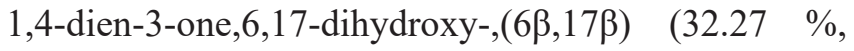
steroid). Furthermore, the highest amount in our DEZSC was palmitic acid (26.92 \%, fatty acid). This chemical compound contained anticancer activity through intercalating with DNA topoisomerase- ${ }^{[36]}$. DEGE displayed similar chemical composition with DEZSC, however, several compounds only found in DEGE were neophytadiene, phytol, linoleic acid, hentriacontane, phytol acetate and heneicosane, in which these compounds were reported for anticancer property ${ }^{[37-42]}$. The limitation of characterization was marked since GC-MS is able to detect only volatile compounds. However, other chemical contents can be analyzed through other spectroscopic methods with a linbrary of spectra to compare with the observed compounds ${ }^{[43]}$. We suggest phytochemical screening techniques such as UltraViolet-Visible spectroscopy ${ }^{[44]}$, Infrared (IR) spectroscopy ${ }^{[45]}$ and Liquid Chromatography Mass Spectroscopy (LC-MS) ${ }^{[46]}$ to analyze other phytocompounds of DEAP, DEZSC and DEGE for further study.

Our individual extract cytotoxicity test revealed that DEAP, DEZSC and DEGE possessed high cytotoxicity. In this study, we attempted to enhance the cytotoxicity of DEAP, DEZSC and DEGE by combining them with PFPE. In the previous study using PFPE, $P$. nigrum dichloromethane crude extract and piperine showed $\mathrm{IC}_{50}$ values of 7.45, 23.46 and $>20 \mu \mathrm{g} . \mathrm{ml}^{-1}$, respectively ${ }^{[19]}$. Based on our previous results, $P$. nigrum extract containing piperine increased

TABLE 3: CYTOTOXICITY OF G. extensum LEAVES PREPARED IN SIX SOLVENTS AGAINST DIFFERENT TYPE OF CANCER CELLS

\begin{tabular}{|c|c|c|c|c|c|c|c|}
\hline \multirow[b]{2}{*}{ Cell Line } & \multicolumn{7}{|c|}{$I_{50}$ value $(\mu \mathrm{g} / \mathrm{ml})(\mu \mathrm{M})^{\mathrm{a}}$} \\
\hline & $\begin{array}{c}\text { FEGE }\left(\mathrm{SI}_{\text {Vero }}\right. \\
\left.\mathrm{SI}_{\mathrm{L-929}}\right)\end{array}$ & $\begin{array}{c}\text { MEGE (SI } \\
\left.\mathrm{SI}_{\mathrm{L-929}}\right)\end{array}$ & $\begin{array}{c}\text { EEGE (SI }{ }_{\text {vero }} \text {, } \\
\left.\mathrm{SI}_{\mathrm{L-929}}\right)\end{array}$ & $\begin{array}{c}\operatorname{DEGE}\left(\mathrm{SI}_{\text {Vero }},\right. \\
\left.\mathrm{SI}_{\mathrm{L}-929}\right)\end{array}$ & $\begin{array}{c}\text { EAGE (SI }{ }_{\text {vero }} \\
\left.\mathrm{SI}_{\mathrm{L-929}}\right)\end{array}$ & $\begin{array}{l}\text { HEGE (SI } \\
\left.\mathrm{SI}_{\text {L-929 }}\right)\end{array}$ & $\begin{array}{c}\operatorname{DOX}\left(\mathrm{SI}_{\text {Vero' }}\right. \\
\left.\mathrm{SI}_{\mathrm{L-929}}\right)\end{array}$ \\
\hline \multicolumn{8}{|c|}{ Breast cancer } \\
\hline MCF-7 & $\begin{array}{l}\text { Not inhibited } \\
\quad(N D, N D)\end{array}$ & $\begin{array}{c}26.34 \pm 0.53 \\
(1.27,1.72)\end{array}$ & $\begin{array}{l}23.67 \pm 1.81 \\
(1.09,2.01)\end{array}$ & $\begin{array}{l}15.58 \pm 1.81 \\
(0.59,1.18)\end{array}$ & $\begin{array}{l}25.56 \pm 0.60 \\
(1.06,1.20)\end{array}$ & $\begin{array}{l}\text { Not inhibited } \\
\quad(N D, N D)\end{array}$ & $\begin{array}{c}1.15 \pm 0.07 \\
(6.84,1.38)\end{array}$ \\
\hline MDA- MB-231 & $\begin{array}{l}\text { Not inhibited } \\
\quad(N D, N D)\end{array}$ & $\begin{array}{l}51.18 \pm 2.07 \\
(0.65,0.88)\end{array}$ & $\begin{array}{c}57.84 \pm 1.31 \\
(0.45,0.82)\end{array}$ & $\begin{array}{c}20.78 \pm 2.01 \\
(0.44,0.88)\end{array}$ & $\begin{array}{l}23.15 \pm 1.57 \\
(1.17,1.33)\end{array}$ & $\begin{array}{l}\text { Not inhibited } \\
\quad(N D, N D)\end{array}$ & $\begin{array}{c}1.57 \pm 0.23 \\
(5.02,1.01)\end{array}$ \\
\hline \multicolumn{8}{|c|}{ Colorectal cancer } \\
\hline HT-29 & $\begin{array}{l}\text { Not inhibited } \\
\quad(N D, N D)\end{array}$ & $\begin{array}{l}25.35 \pm 1.94 \\
(1.32,1.78)\end{array}$ & $\begin{array}{l}29.68 \pm 2.04 \\
(0.87,1.60)\end{array}$ & $\begin{array}{c}19.86 \pm 0.61 \\
(0.46,0.92)\end{array}$ & $\begin{array}{l}33.63 \pm 2.16 \\
(0.81,0.91)\end{array}$ & $\begin{array}{l}\text { Not inhibited } \\
\quad(N D, N D)\end{array}$ & $\begin{array}{c}2.53 \pm 0.56 \\
(3.11,0.63)\end{array}$ \\
\hline SW-620 & $\begin{array}{l}\text { Not inhibited } \\
\quad(N D, N D)\end{array}$ & $\begin{array}{l}23.27 \pm 1.54 \\
(1.43,1.94)\end{array}$ & $\begin{array}{c}17.03 \pm 0.09 \\
(1.52,2.79)\end{array}$ & $\begin{array}{c}20.09 \pm 2.03 \\
(0.46,0.91)\end{array}$ & $\begin{array}{l}27.83 \pm 2.20 \\
(0.97,1.10)\end{array}$ & $\begin{array}{l}\text { Not inhibited } \\
\quad(N D, N D)\end{array}$ & $\begin{array}{c}3.15 \pm 0.62 \\
(2.50,0.5)\end{array}$ \\
\hline \multicolumn{8}{|c|}{ Ovarian cancer } \\
\hline A2780 & $\begin{array}{l}\text { Not inhibited } \\
\quad(N D, N D)\end{array}$ & $\begin{array}{c}16.12 \pm 1.40 \\
(2.07,2.81)\end{array}$ & $\begin{array}{l}41.21 \pm 1.23 \\
(0.63,1.15)\end{array}$ & $\begin{array}{c}10.08 \pm 0.04 \\
(0.91,1.82)\end{array}$ & $\begin{array}{c}15.22 \pm 0.58 \\
(1.78,2.02)\end{array}$ & $\begin{array}{c}43.16 \pm 1.51 \\
(N D, N D)\end{array}$ & $\begin{array}{c}2.33 \pm 0.18 \\
(3.38,0.68)\end{array}$ \\
\hline SKOV-3 & $\begin{array}{l}\text { Not inhibited } \\
\quad(N D, N D)\end{array}$ & $\begin{array}{l}\text { Not inhibited } \\
\quad(\mathrm{ND}, \mathrm{ND})\end{array}$ & $\begin{array}{l}\text { Not inhibited } \\
\quad(N D, N D)\end{array}$ & $\begin{array}{l}29.95 \pm 1.12 \\
(0.31,0.61)\end{array}$ & $\begin{array}{l}\text { Not inhibited } \\
\quad(N D, N D)\end{array}$ & $\begin{array}{l}\text { Not inhibited } \\
\quad(N D, N D)\end{array}$ & $\begin{array}{c}1.64 \pm 0.19 \\
(4.80,0.97)\end{array}$ \\
\hline \multicolumn{8}{|c|}{ Non-cancerous } \\
\hline Vero & Not inhibited & $33.39 \pm 1.59$ & $25.90 \pm 0.47$ & $9.16 \pm 0.8$ & $27.08 \pm 3.03$ & Not inhibited & $7.88 \pm 0.43$ \\
\hline L-929 & Not inhibited & $45.23 \pm 2.43$ & $47.57 \pm 0.35$ & $18.37 \pm 0.66$ & $30.73 \pm 3.32$ & Not inhibited & $1.59 \pm 0.18$ \\
\hline
\end{tabular}

Data represented mean $\pm \mathrm{SD}$ from three independent experiments. $\mathrm{SI}_{\text {Vero }}$ or $\mathrm{SI}_{\mathrm{L}-929}$ cells are selectivity index, calculated by dividing $\mathrm{IC}_{50}$ of

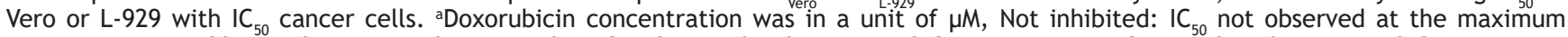
concentration at $80 \mu \mathrm{g} / \mathrm{ml}$, ND: not determined, FEGE: freeze-dried extract of $G$. extensum, MEGE: methanol extract of $G$. extensum, EEGE: ethanol extract of $G$. extensum, DEGE: dichloromethane extract of $G$. extensum, EAGE: ethyl acetate extract of $G$. extensum, HEGE: hexane extract of $G$. extensum 
$\mathrm{IC}_{50}$ which attenuated the cytotoxic effect on cancer cells. Moreover, phytocompounds of PFPE such as piperanine, pipericine, 2,4,14-eicosatrienamide and retrofractamide-A showed hepatoprotective activity which may protect non-cancerous cell lines from cytotoxic compounds ${ }^{[20]}$. Thus, we combined those three extracts with PFPE. The results showed that DEAP combination with PFPE provided antagonistic effect for the whole ratio against HT-29 and SW-620 cells. The combination of DEZSC with PFPE had an antagonistic effect on MCF-7 and A2780 cells. The observation on antagonistic effect emphasizes that phytocompounds of DEAP and DEZSC were not able to collaborate with compounds of PFPE. Steroids, fatty alcohols and fatty acids were detected in DEAP and DEZSC, from GC-MS results (fig. 1). Cholesterol is an initial form for synthesizing steroids. Meanwhile, fatty alcohols and fatty acids are the derivatives of lipids that can generate cholesterols. In contrast, caryophyllene which contained in PFPE exhibited anti-hypercholesterolemic or hyperlipid preventive activity ${ }^{[47]}$. Caryophyllene could additionally attenuate lipid accumulation on hepatic tissue which linked to the stimulation of AMP-activated protein kinase (AMPK) phosphorylation, a crucial enzyme in lipid metabolism. Caryophyllene also induces degradation of fatty acid synthase (FAS) ${ }^{[48]}$. The different roles in caryophyllene and lipid-derivatives (fatty acids, steroids and fatty alcohols) could pinpoint the antagonistic effect of this combination (Tables 4-7).

Surprisingly, our investigation revealed that a combination of DEGE with PFPE remarkably showed synergistic interaction on MCF-7 cells. We had tried to identify possible synergic chemical compounds. As we mentioned previously, palmitic acid and kusunokinin showed intercalation to DNA topoisomerase-I together with PFPE, enabling degradation of DNA topoisomerase-II ${ }^{[36,49]}$. Due to their important role as a DNA controller, DNA topoisomerase-I and DNA topoisomerase-II are targeted for promising anticancer treatment ${ }^{[50,51]}$. A synergistic effect against MCF-7 cells from a PFPE-combined DEGE led to a further study for the relevant information to strengthen our hypothesis that MCF-7 cells could not escape from cell death since it was attacked by several death pathways of this combination. These expected mechanisms accordingly convinced us to conduct a study regarding an apoptotic (cell death) process.

Apoptosis and multi caspase activity experiments were investigated using annexin $\mathrm{V} /$ propidium iodide assay and multi caspase/7-AAD assay. In the assay, the total

TABLE 4: CHEMICAL CONSTITUENTS AND BIOLOGICAL PROPERTIES OF COMPOUNDS OF DICHLOROMETHANE CRUDE EXTRACT OF A. paniculata (DEAP) IDENTIFIED THROUGH GC-MS ANALYSIS

\begin{tabular}{|c|c|c|c|c|c|}
\hline RT (min) & Identified compound & Formula & $\begin{array}{l}\text { Molecular mass } \\
\left(\mathrm{g} \mathrm{mol}^{-1}\right)\end{array}$ & Area (\%) & $\begin{array}{l}\text { Nature of } \\
\text { compound }\end{array}$ \\
\hline 17.34 & Furfuryl alcohol & $\mathrm{C}_{5} \mathrm{H}_{10} \mathrm{O}_{2}$ & 102.13 & 0.01 & Alcohol \\
\hline 21.28 & Octadecane & $\mathrm{C}_{18} \mathrm{H}_{38}$ & 254.5 & 0.02 & Hydrocarbon \\
\hline 29.72 & Neophytadiene & $\mathrm{C}_{20} \mathrm{H}_{38}$ & 278.5 & 1.2 & Terpene \\
\hline 29.83 & $\begin{array}{l}\text { 6,10,14-trimethyl pentadecane- } \\
\text { 2-one }\end{array}$ & $\mathrm{C}_{18} \mathrm{H}_{36} \mathrm{O}$ & 268.5 & 0.53 & Terpene \\
\hline 31.24 & 2-Methyltetradecanal & $\mathrm{C}_{15} \mathrm{H}_{30} \mathrm{O}$ & 226.4 & 0.03 & Aldehyde \\
\hline 32.17 & Palmitic acid & $\mathrm{C}_{16} \mathrm{H}_{32} \mathrm{O}_{2}$ & 256.42 & 1.24 & Fatty acid \\
\hline 33.3 & 2-octylacolein & $\mathrm{C}_{11} \mathrm{H}_{20} \mathrm{O}$ & 168.28 & 0.01 & Hydrocarbon \\
\hline 34.74 & 3,7-Dimethyl-2,3-epoxyoctanal & $\mathrm{C}_{10} \mathrm{H}_{18} \mathrm{O}_{2}$ & 170.25 & 0.01 & Aldehyde \\
\hline 38.16 & Tricosane & $\mathrm{C}_{23} \mathrm{H}_{48}$ & 324.6 & 0.03 & Hydrocarbon \\
\hline 42.09 & $\begin{array}{l}\text { 1,2-Benzenedicarboxylic acid, } \\
\text { bis(2-ethylhexyl) ester }\end{array}$ & $\mathrm{C}_{24} \mathrm{H}_{38} \mathrm{O}_{4}$ & 390.6 & 0.25 & Phthalate \\
\hline 47.09 & $\begin{array}{c}\text { 2-oxobutanoic acid neopentyl } \\
\text { ester }\end{array}$ & $\mathrm{C}_{9} \mathrm{H}_{16} \mathrm{O}_{3}$ & 172.22 & 0.01 & Carboxylic acid \\
\hline 49.91 & 1-Heptatriacotanol & $\mathrm{C}_{37} \mathrm{H}_{76} \mathrm{O}$ & 537 & 60.29 & Alcohol \\
\hline 50.14 & a-Tocopherol & $\mathrm{C}_{29} \mathrm{H}_{50} \mathrm{O}_{2}$ & 430.7 & 0.05 & Tocopherol \\
\hline 50.45 & $\begin{array}{l}\text { Androsta-1,4-dien-3-one, 6,17- } \\
\text { dihydroxy-, }(6 B, 17 \mathrm{~B})\end{array}$ & $\mathrm{C}_{19} \mathrm{H}_{26} \mathrm{O}_{3}$ & 302.4 & 32.27 & Steroid \\
\hline 51.59 & Stigmasterol & $\mathrm{C}_{29} \mathrm{H}_{48} \mathrm{O}$ & 412.7 & 0.98 & Steroid \\
\hline 52.29 & $\mathrm{Y}$-Sitosterol & $\mathrm{C}_{29} \mathrm{H}_{50} \mathrm{O}$ & 414.7 & 3.04 & Terpene \\
\hline 52.65 & B-Amyrin & $\mathrm{C}_{30} \mathrm{H}_{50} \mathrm{O}$ & 426.7 & 0.02 & Terpene \\
\hline
\end{tabular}


TABLE 5: CHEMICAL CONSTITUENTS AND BIOLOGICAL PROPERTIES OF COMPOUNDS OF DICHLOROMETHANE CRUDE EXTRACT OF Z. spina-christi (DEZSC) IDENTIFIED THROUGH GC-MS ANALYSIS

\begin{tabular}{|c|c|c|c|c|c|}
\hline RT (min) & Identified compound & Formula & $\begin{array}{l}\text { Molecular mass } \\
\quad\left(\mathrm{g} \mathrm{mol}^{-1}\right)\end{array}$ & Area (\%) & $\begin{array}{l}\text { Nature of } \\
\text { compound }\end{array}$ \\
\hline 28.06 & Myristic acid & $\mathrm{C}_{14} \mathrm{H}_{28} \mathrm{O}_{2}$ & 228.37 & 1.33 & Fatty acid \\
\hline 29.64 & Neophytadiene & $\mathrm{C}_{20} \mathrm{H}_{38}$ & 278.52 & 7.91 & Terpene \\
\hline 29.75 & 6,10,14-trimethyl pentadecane-2-one & $\mathrm{C}_{18} \mathrm{H}_{36} \mathrm{O}$ & 268.48 & 1.79 & Terpene \\
\hline 30.14 & Phytol, acetate & $\mathrm{C}_{22} \mathrm{H}_{42} \mathrm{O}_{2}$ & 338.57 & 1.28 & Terpene \\
\hline 30.49 & Phytol & $\mathrm{C}_{20} \mathrm{H}_{40} \mathrm{O}$ & 296.53 & 4.07 & Terpene \\
\hline 32.22 & Palmitic acid & $\mathrm{C}_{16} \mathrm{H}_{32} \mathrm{O}_{2}$ & 256.42 & 26.92 & Fatty acid \\
\hline 35.31 & Linoleic acid & $\mathrm{C}_{18} \mathrm{H}_{32} \mathrm{O}_{2}$ & 280.46 & 6.76 & Fatty acid \\
\hline 35.41 & Linolenic acid & $\mathrm{C}_{18} \mathrm{H}_{30} \mathrm{O}_{2}$ & 278.43 & 11.22 & Fatty acid \\
\hline 35.81 & Stearic acid & $\mathrm{C}_{18} \mathrm{H}_{36} \mathrm{O}_{2}$ & 284.48 & 3.8 & Fatty acid \\
\hline 38.93 & $\begin{array}{l}\text { 4,8,12,16-Tetramethylheptadecan-4- } \\
\text { olide }\end{array}$ & $\mathrm{C}_{21} \mathrm{H}_{40} \mathrm{O}_{2}$ & 324.54 & 0.71 & $\begin{array}{l}\text { Furan } \\
\text { hydrocarbon }\end{array}$ \\
\hline 41.99 & Bis(2-ethylhexyl) phthalate & $\mathrm{C}_{24} \mathrm{H}_{38} \mathrm{O}_{4}$ & 390.56 & 0.88 & Phthalate \\
\hline 46.04 & Squalene & $\mathrm{C}_{30} \mathrm{H}_{50}$ & 410.72 & 1.68 & Terpene \\
\hline 46.37 & a-Tocospiro A & $\mathrm{C}_{29} \mathrm{H}_{50} \mathrm{O}_{4}$ & 462.7 & 1.34 & Tocopherol \\
\hline 46.67 & a-Tocospiro B & $\mathrm{C}_{29} \mathrm{H}_{50} \mathrm{O}_{4}$ & 462.7 & 1.44 & Tocopherol \\
\hline 46.99 & n-Tetracosanol-1 & $\mathrm{C}_{24} \mathrm{H}_{50} \mathrm{O}$ & 354.65 & 6.07 & Fatty alcohol \\
\hline 48.97 & Y-Tocopherol & $\mathrm{C}_{28} \mathrm{H}_{48} \mathrm{O}_{2}$ & 416.68 & 1.11 & Tocopherol \\
\hline 49.63 & Octacosanol & $\mathrm{C}_{28} \mathrm{H}_{58} \mathrm{O}$ & 410.76 & 5.26 & Fatty alcohol \\
\hline 50.01 & Vitamin E & $\mathrm{C}_{29} \mathrm{H}_{50} \mathrm{O}_{2}$ & 430.71 & 0.77 & Tocopherol \\
\hline 51.08 & Campesterol & $\mathrm{C}_{28} \mathrm{H}_{48} \mathrm{O}$ & 400.68 & 1.04 & Steroid \\
\hline 51.49 & Stigmasterol & $\mathrm{C}_{29} \mathrm{H}_{48} \mathrm{O}$ & 412.69 & 4.91 & Steroid \\
\hline 52.19 & Stigmast-5-en-3-ol & $\mathrm{C}_{29} \mathrm{H}_{50} \mathrm{O}$ & 414.7 & 5.24 & Steroid \\
\hline 52.83 & Lupenone & $\mathrm{C}_{30} \mathrm{H}_{48} \mathrm{O}$ & 424.7 & 2.91 & Terpene \\
\hline 53.09 & Lupeol & $\mathrm{C}_{30} \mathrm{H}_{50} \mathrm{O}$ & 426.72 & 1.91 & Terpene \\
\hline
\end{tabular}

RT: Retention time

TABLE 6: CHEMICAL CONSTITUENTS AND BIOLOGICAL PROPERTIES OF COMPOUNDS OF DICHLOROMETHANE CRUDE EXTRACT OF G. extensum (DEGE) IDENTIFIED THROUGH GC-MS ANALYSIS

\begin{tabular}{|c|c|c|c|c|c|}
\hline RT (min) & Compound name & Formula & Molecular mass $\left(\mathrm{g} \mathrm{mol}^{-1}\right)$ & Area (\%) & Compound nature \\
\hline 15.68 & 1,2-Di-tert-butylbenzene & $\mathrm{C}_{14} \mathrm{H}_{22}$ & 190.32 & 0.08 & Phenylpropane \\
\hline 17.92 & 2-Chlorohexylacetate & $\mathrm{C}_{8} \mathrm{H}_{15} \mathrm{ClO}_{2}$ & 178.66 & 0.02 & Carboxylic acid \\
\hline 22.1 & Pentadecane & $\mathrm{C}_{15} \mathrm{H}_{32}$ & 212.41 & 0.02 & Hydrocarbon \\
\hline 22.49 & $\begin{array}{c}\text { 5-Isopropyl-4-(trifluoromethyl)-1H- } \\
\text { pyrimidin-2-one }\end{array}$ & $\mathrm{C}_{8} \mathrm{H}_{9} \mathrm{~F}_{3} \mathrm{~N}_{2} \mathrm{O}$ & 206.17 & 0.04 & Alkaloid \\
\hline 22.85 & Dihydroactinidiolide & $\mathrm{C}_{11} \mathrm{H}_{16} \mathrm{O}_{2}$ & 180.24 & 0.47 & Benzofuran \\
\hline 27.44 & $\begin{array}{c}\text { Heptanoic acid, tridecafluoro-heptyl } \\
\text { ester }\end{array}$ & $\mathrm{C}_{14} \mathrm{H}_{15} \mathrm{~F}_{13} \mathrm{O}_{2}$ & 462.25 & 0.02 & Fatty acid ester \\
\hline 28.14 & Loliolide & $\mathrm{C}_{11} \mathrm{H}_{16} \mathrm{O}_{3}$ & 196.24 & 1.64 & Benzofuran \\
\hline 29.62 & 1-dodecanol & $\mathrm{C}_{12} \mathrm{H}_{26} \mathrm{O}$ & 186.33 & 0.05 & Fatty alcohol \\
\hline 29.72 & Neophytadiene & $\mathrm{C}_{20} \mathrm{H}_{38}$ & 278.5 & 19.36 & Terpene \\
\hline 29.83 & $\begin{array}{l}6,10,14 \text {-trimethyl } \\
\text { pentadecane-2-one }\end{array}$ & $\mathrm{C}_{18} \mathrm{H}_{36} \mathrm{O}$ & 268.5 & 1.93 & Terpene \\
\hline 30.21 & Phytol & $\mathrm{C}_{20} \mathrm{H}_{40} \mathrm{O}$ & 296.5 & 13.36 & Terpene \\
\hline 31.23 & 2-Methyloctanal & $\mathrm{C}_{9} \mathrm{H}_{18} \mathrm{O}$ & 142.24 & 0.04 & Aldehyde \\
\hline 32.12 & $\begin{array}{c}\text { 1,2-Benzenedicarboxylic acid, dibutyl } \\
\text { ester }\end{array}$ & $\mathrm{C}_{16} \mathrm{H}_{22} \mathrm{O}_{4}$ & 278.34 & 0.19 & $\begin{array}{l}\text { Benzoic acid } \\
\text { ester }\end{array}$ \\
\hline 32.24 & Palmitic acid & $\mathrm{C}_{16} \mathrm{H}_{32} \mathrm{O}_{2}$ & 256.42 & 21.4 & Fatty acid \\
\hline 34.42 & Pentatriacontane & $\mathrm{C}_{35} \mathrm{H}_{72}$ & 492.9 & 0.34 & Hydrocarbon \\
\hline 35.36 & Linoleic acid & $\mathrm{C}_{18} \mathrm{H}_{32} \mathrm{O}_{2}$ & 280.4 & 6.7 & Fatty acid \\
\hline 35.48 & Linolenic acid & $\mathrm{C}_{18} \mathrm{H}_{30} \mathrm{O}_{2}$ & 278.4 & 12.08 & Fatty acid \\
\hline 36.52 & 4-Tridecen-2-ynal, (Z)- & $\mathrm{C}_{13} \mathrm{H}_{20} \mathrm{O}$ & 192.3 & 0.06 & Hydrocarbon \\
\hline 43.99 & 3-Penten-2-one & $\mathrm{C}_{5} \mathrm{H}_{8} \mathrm{O}$ & 84.12 & 0.05 & Ketone \\
\hline
\end{tabular}

RT: Retention time 


\begin{tabular}{|c|c|c|c|c|c|c|c|}
\hline Combination & Cell line & Ratio Extract:PFPE & $\begin{array}{l}\text { Extract } \\
\text { Conc. } \\
(\mu \mathrm{g} / \mathrm{ml})\end{array}$ & $\begin{array}{l}\text { PFPE } \\
\text { Conc. } \\
(\mu \mathrm{g} / \mathrm{ml})\end{array}$ & \% inhibition & $\mathrm{Cl}$ & Interaction \\
\hline \multirow{8}{*}{ DEAP+PFPE } & \multirow{4}{*}{ HT-29 } & $I C_{50}: I C_{50}$ & 8.93 & 17.63 & $82.35 \pm 1.13$ & $1.12 \pm 0.04$ & $\begin{array}{c}\text { Slight } \\
\text { antagonism }\end{array}$ \\
\hline & & $0.5 \mathrm{IC}_{50}: \mathrm{IC}_{50}$ & 4.46 & 17.63 & $54.89 \pm 1.34$ & $1.86 \pm 0.05$ & Antagonism \\
\hline & & $\mathrm{IC}_{50}: 0.5 \mathrm{IC}_{50}$ & 8.93 & 8.82 & $47.37 \pm 2.45$ & $1.74 \pm 0.08$ & Antagonism \\
\hline & & $0.5 I C_{50}: 0.5 I C_{50}$ & 4.46 & 8.82 & $34.21 \pm 0.24$ & $1.73 \pm 0.01$ & Antagonism \\
\hline & \multirow{4}{*}{ SW-620 } & $I C_{50}: I C_{50}$ & 7.49 & 11.3 & $81.20 \pm 1.55$ & $1.09 \pm 0.06$ & Nearly additive \\
\hline & & $0.5 I C_{50}: I C_{50}$ & 3.74 & 11.3 & $67.68 \pm 1.25$ & $1.29 \pm 0.04$ & $\begin{array}{c}\text { Slight } \\
\text { antagonism }\end{array}$ \\
\hline & & $\mathrm{IC}_{50}: 0.5 \mathrm{IC}_{50}$ & 7.49 & 5.65 & $65.58 \pm 0.77$ & $1.14 \pm 0.01$ & $\begin{array}{c}\text { Slight } \\
\text { antagonism }\end{array}$ \\
\hline & & $0.5 \mathrm{IC}_{50}: 0.5 \mathrm{IC}_{50}$ & 3.74 & 5.65 & $43.00 \pm 1.2$ & $1.33 \pm 0.03$ & $\begin{array}{c}\text { Slight } \\
\text { antagonism }\end{array}$ \\
\hline \multirow{8}{*}{ DEZSC+PFPE } & \multirow{4}{*}{ MCF-7 } & $I C_{50}: I C_{50}$ & 13.35 & 21.06 & $78.65 \pm 4.33$ & $1.19 \pm 0.16$ & $\begin{array}{c}\text { Slight } \\
\text { antagonism }\end{array}$ \\
\hline & & $0.5 \mathrm{IC}_{50}: \mathrm{IC}_{50}$ & 6.675 & 21.06 & $50.4 \pm 2.65$ & $1.86 \pm 0.11$ & Antagonism \\
\hline & & $I C_{50}: 0.5 I C_{50}$ & 13.35 & 10.53 & $82.66 \pm 2.65$ & $0.72 \pm 0.07$ & $\begin{array}{l}\text { Moderate } \\
\text { synergism }\end{array}$ \\
\hline & & $0.5 \mathrm{IC}_{50}: 0.5 \mathrm{IC}_{50}$ & 6.675 & 10.53 & $37.07 \pm 1.05$ & $1.52 \pm 0.04$ & Antagonism \\
\hline & \multirow{4}{*}{ A2780 } & $I C_{50}: I_{50}$ & 14.64 & 21.12 & $72.46 \pm 5.09$ & $1.39 \pm 0.07$ & $\begin{array}{c}\text { Slight } \\
\text { antagonism }\end{array}$ \\
\hline & & $0.5 I C_{50}: I C_{50}$ & 7.32 & 21.12 & $13.59 \pm 4.36$ & $4.77 \pm 0.91$ & $\begin{array}{c}\text { Strong } \\
\text { antagonism }\end{array}$ \\
\hline & & $\mathrm{IC}_{50}: 0.5 \mathrm{IC}_{50}$ & 14.64 & 10.56 & $48.7 \pm 8.73$ & $1.66 \pm 0.30$ & Antagonism \\
\hline & & $0.5 \mathrm{IC}_{50}: 0.5 \mathrm{IC} \mathrm{C}_{50}$ & 7.32 & 10.56 & $14.15 \pm 9.69$ & $3.21 \pm 1.36$ & $\begin{array}{c}\text { Strong } \\
\text { antagonism }\end{array}$ \\
\hline \multirow{8}{*}{ DEGE+PFPE } & \multirow{4}{*}{ MCF-7 } & $I C_{50}: I_{50}$ & 15.58 & 21.06 & $97.29 \pm 0.33$ & $0.36 \pm 0.03$ & Synergism \\
\hline & & $0.5 \mathrm{IC}_{50}: \mathrm{IC} \mathrm{C}_{50}$ & 7.79 & 21.06 & $93.65 \pm 3.72$ & $0.44 \pm 0.14$ & Synergism \\
\hline & & $\mathrm{IC}_{50}: 0.5 \mathrm{IC}_{50}$ & 15.58 & 10.53 & $95.32 \pm 1.5$ & $0.34 \pm 0.06$ & Synergism \\
\hline & & $0.5 I_{50}: 0.5 I C_{50}$ & 7.79 & 10.53 & $37.69 \pm 4.12$ & $1.46 \pm 0.13$ & Antagonism \\
\hline & \multirow{4}{*}{ A2780 } & $I C_{50}: I C_{50}$ & 10.08 & 21.12 & $80.41 \pm 1.97$ & $1.22 \pm 0.08$ & $\begin{array}{c}\text { Slight } \\
\text { antagonism }\end{array}$ \\
\hline & & $0.5 \mathrm{IC}_{50}: \mathrm{IC}_{50}$ & 5.04 & 21.12 & $10.11 \pm 4.19$ & $6.70 \pm 1.61$ & $\begin{array}{c}\text { Strong } \\
\text { antagonism }\end{array}$ \\
\hline & & $\mathrm{IC}_{50}: 0.5 \mathrm{IC}_{50}$ & 10.08 & 10.56 & $51.22 \pm 4.84$ & $1.63 \pm 0.16$ & Antagonism \\
\hline & & $0.5 I C_{50}: 0.5 I C_{50}$ & 5.04 & 10.56 & $5.54 \pm 2.14$ & $5.55 \pm 1.18$ & $\begin{array}{c}\text { Strong } \\
\text { antagonism }\end{array}$ \\
\hline
\end{tabular}

Data represented mean $\pm S D$ from three independent experiments. $\mathrm{Cl}$ is combination index, analyzed by compusyn software. DEAP: dichloromethane extract of $A$. paniculata, DEZSC: dichloromethane extract of $Z$. spina-christi, DEGE: dichloromethane extract of $G$. extensum, PFPE: low piperine fractional $P$. nigrum extract

apoptotic cells were obtained from a summation of early and late apoptotic cells. The early and later apoptosis stage could be distinguished by intercalation among Annexin $\mathrm{V}$ to Phosphatidylserine and intercalation of Annexin V together with PI inside permeable membrane of late apoptotic cells. Meanwhile, dead or necrotic cells were observed in this study. The different aspect of these two basic types of cell death is that the necrosis is caused by excessive external damage, while apoptosis occurs when the cells are aged and undergo progressive morphological alteration by internal molecular involvement ${ }^{[52]}$. Dot plots in fig. 2 reflected all cell conditions including live cells, early and late apoptotic cells and dead cells (necrotic cells).
A significant decrease of live cells was found in MCF-7 cells at $72 \mathrm{~h}$ after the incubation with the combination of DEGE and PFPE. Moreover, late apoptotic and total apoptotic cells were increased statistically significantly at $72 \mathrm{~h}$ after the treatment and responded in a timedependent manner.

The apoptosis insight can be harnessed as a key strategy for novel targeted therapies that lead to the arrest of cancer cell growth and spread ${ }^{[53]}$. Moreover, the correlation between apoptosis and caspase activation is the loss of mitochondrial membrane potential. An activation of cytochrome c (cyt-c) would be then followed by caspase activation ${ }^{[54]}$. The caspases are activated when the cell inactivates zymogens, provoking 
www.ijpsonline.com
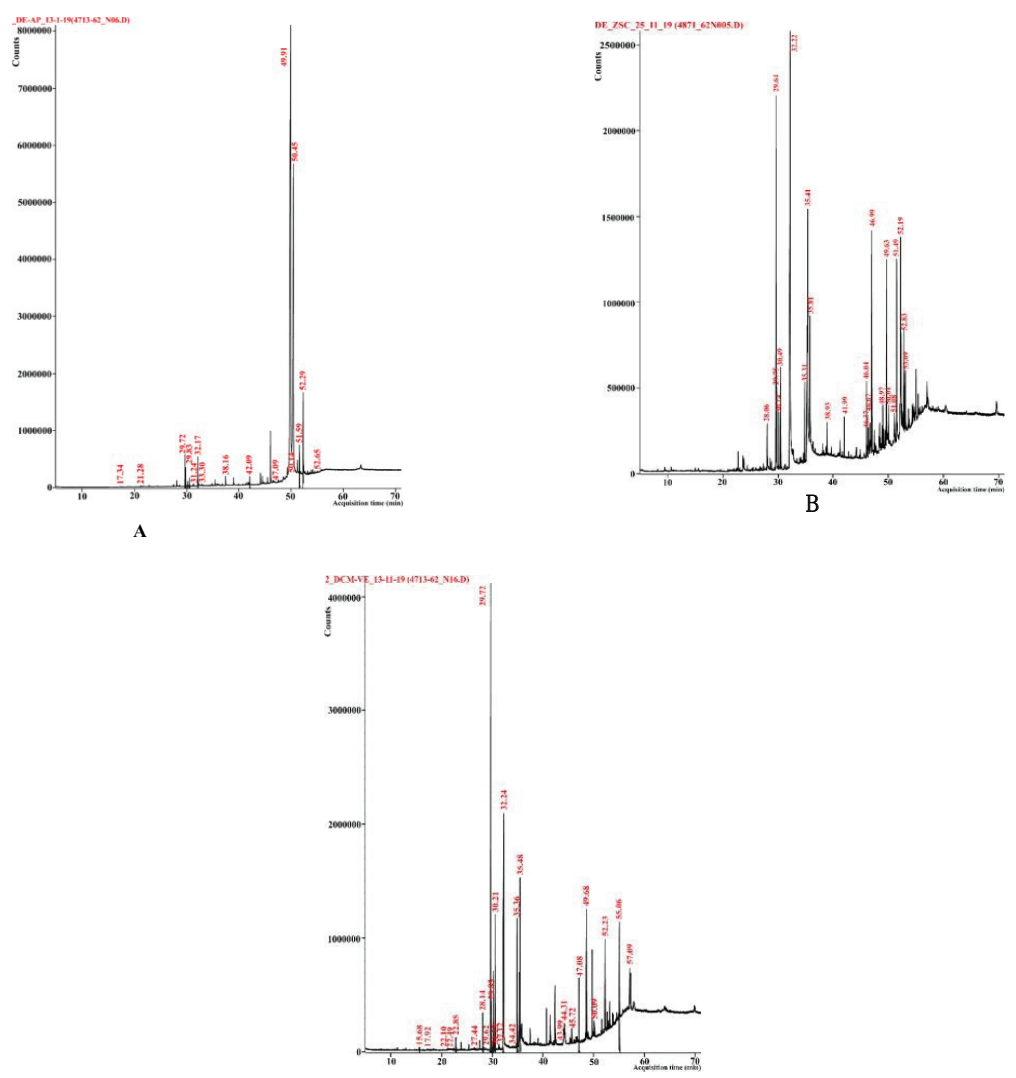

Fig. 1: GC-MS chromatographic profile of extracts: (A) DEAP, (B) DEZSC and (C) DEGE
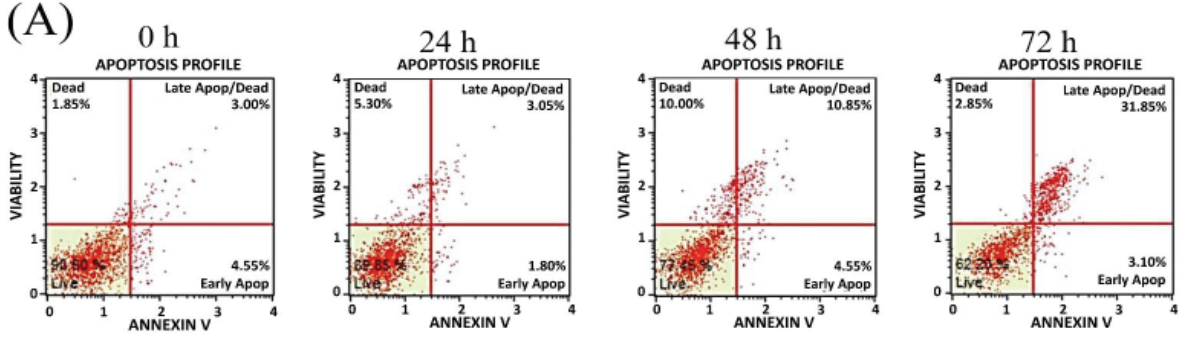

(B)

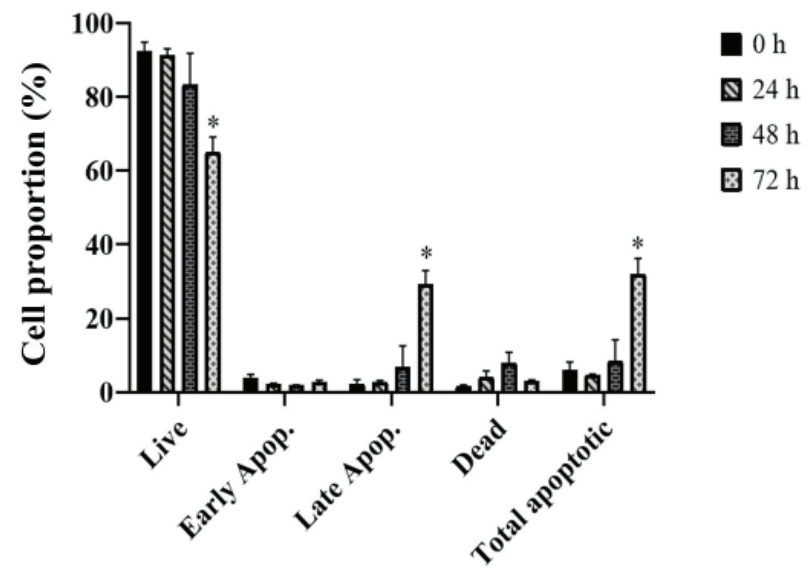

Fig. 2: The combination of DEGE with PFPE induces cell apoptosis

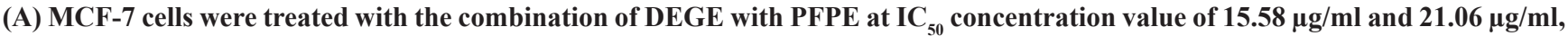
respectively and incubated for 24,48 and $72 \mathrm{~h}$. After treatment, apoptotic cells were analyzed by the Muse ${ }^{\circledR}$ Annexin V-FITC assay and Propidium Iodide (dead cell kit). (B) The graph represented the summary of average percentages \pm SD of live, early apoptotic, late apoptotic, dead and total apoptotic of three independent experiments. The statistical analysis of the data was tested by Student $t$ test where $p$ values less than 0.05 was statistically considered as significant differences compared to control group at $0 \mathrm{~h}$ 

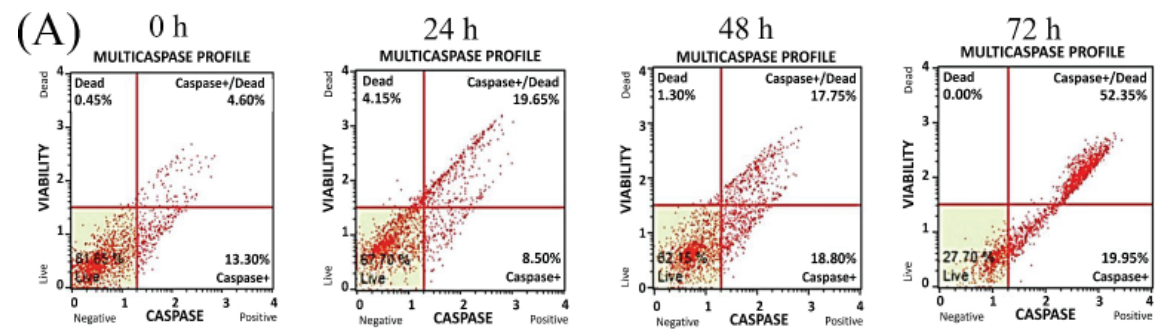

(B)

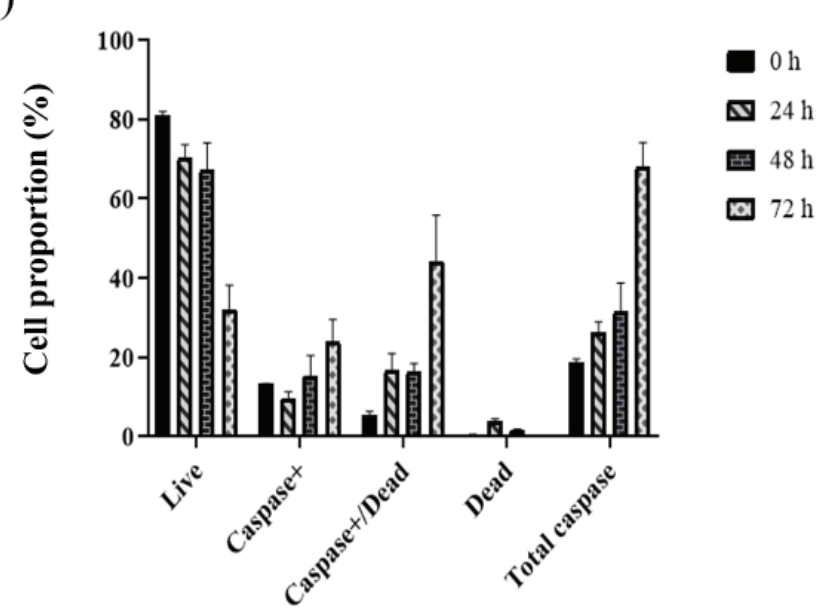

Fig. 3: The combination of DEGE with PFPE induces multi caspase activity

(A) MCF-7 cells were treated with the combination of DEGE with PFPE at IC s0 $_{50}$ contration value of $15.58 \mu \mathrm{g} / \mathrm{ml} \mathrm{and} 21.06 \mu \mathrm{g} / \mathrm{ml}$, respectively and incubated for 24,48 and $72 \mathrm{~h}$. After treatment, multi caspase activity was analyzed by the Muse ${ }^{\circledR}$ Multi caspase assay and 7-AAD (dead cell kit). (B) The graph is represented the average percentages \pm SD of live, caspase + , caspase + /dead and total caspase of three independent experiments. The statistical analysis of the data was tested by Student t-test where $p$ values less than 0.05 was statistically considered as significant differences compared to control group at $0 \mathrm{~h}$

a low number of protease activity ${ }^{[55]}$. The dot plots, in fig. 3, represented the proportion of live, caspase+, caspase+/dead and dead cells of MCF-7 cells treated with the combination of DEGE and PFPE. We found that multi caspase activity was significantly increased at $72 \mathrm{~h}(\mathrm{p}<0.05)$ after treatment and responded in a timedependent manner similar to the apoptosis experiment. However, further analysis of proteins in the apoptosis pathway would be encouraged.

To the best of our insight, we analyzed and linked to the compounds observed by GC-MS. Several previous findings revealed that the chemical compositions of DEGE could affect apoptotic associated proteins and caspases. The most abundant phytocompound of DEGE was palmitic acid, which can promotes caspase $-3,-8$ and -9 activities in Pheochromocytoma cells $(\mathrm{PC} 12)^{[56]}$. Furthermore, linoleic acid, phytol and stigmasterol up regulate apoptotic proteins, such as bax, caspase -3 and -9 . These three compounds also downregulate bcl-2 in colorectal, liver and Non-small cell lung cancer (NSCLC) cells, respectively ${ }^{[38,39,57]}$. Surprisingly, Western blot analysis of PFPE reflected that PFPE was able to regulate the apoptosis associated proteins including $\mathrm{p} 53$, bax and suppress bcl-2 expression on cholangiocarcinoma cells (KKU-M213 and TFK-1)
${ }^{[20]}$. Merged all results together, this report points out that DEGE and PFPE would be a potential regimen for breast cancer treatment in the future. Nevertheless, an in vivo study using breast cancer and clinical trials remain necessary to support supplementary information.

In conclusion, dichloromethane extract of $A$. paniculata, $Z$. spina-christi and $G$. extensum showed strong cytotoxicity against colorectal, breast and ovarian cancer, respectively, with an $\mathrm{IC}_{50}$ value less than $14 \mu \mathrm{g} /$ $\mathrm{ml}$. A combination of dichloromethane crude extract of $G$. extensum with $P$. nigrum crude extract interestingly enhanced a synergistic anticancer activity on breast cancer through the apoptosis induction.

\section{Acknowledgements:}

This work was supported by the Thailand's Education Hub for the Southern Region of ASEAN Countries (TEH-AC) Scholarship from Prince of Songkla University (Contract No. 004/2018); Graduate School, Prince of Songkla University, Thailand; the Agricultural Research Development Agency (Public Organization) (CRP6205031530), Thailand.

\section{Conflict of Interests:}


The authors declared no conflict of interest.

\section{REFERENCES}

1. Thun MJ, DeLancey JO, Center MM, Jemal A, Ward EM. The global burden of cancer: priorities for prevention. Carcinogenesis 2010;31(1):100-10.

2. Bray F, Ferlay J, Soerjomataram I, Siegel RL, Torre LA, Jemal A. Global cancer statistics 2018: GLOBOCAN estimates of incidence and mortality worldwide for 36 cancers in 185 countries. CA Cancer J Clin 2018;68(6):394-424.

3. Coalition WO. The world ovarian cancer coalition atlas. Global Trends in Incidence, Mortality and Survival; 2018.

4. Wang X, Zhang H, Chen X. Drug resistance and combating drug resistance in cancer. Cancer Drug Resist 2019;2(2):14160 .

5. Solowey E, Lichtenstein M, Sallon S, Paavilainen H, Solowey E, Lorberboum-Galski H. Evaluating medicinal plants for anticancer activity. Sci World J; 2014.

6. Hossain MD, Urbi Z, Sule A, Rahman KM. Andrographis paniculata (Burm. f.) Wall. ex Nees: a review of ethnobotany, phytochemistry and pharmacology. Sci World J; 2014.

7. Nkafamiya II, Shagal MH, Haruna M. Potential of Ziziphus spina-christi seed ethanolic extract on inhibition of microbial growth. Acad J Biotechnol 2013;1(4):53-6.

8. Bunwong S, Chantaranothai P, Keeley SC. Revisions and key to the Vernonieae (Compositae) of Thailand. PhytoKeys 2014;(37):25-101.

9. Siripong P, Kongkathip B, Preechanukool K, Picha P, Tunsuwan K, Taylor WC. Cytotoxic diterpenoid constituents from Andrographis paniculata Nees leaves. J Sci Soc Thailand 1992;18(4):187-94.

10. Kumar RA, Sridevi K, Kumar NV, Nanduri S, Rajagopal S. Anticancer and immunostimulatory compounds from Andrographis paniculata. J Ethnopharmacol 2004;92:291-5.

11. Cheung HY, Cheung SH, Li J, Cheung CS, Lai WP, Fong WF, et al. Andrographolide isolated from Andrographis paniculata induces cell cycle arrest and mitochondrial-mediated apoptosis in human leukemic HL-60 cells. Planta Med 2005;71(12):110611.

12. Sukardiman, Studiawan H, Rahman A, Santosa MH, Pratama FA. Ethyl acetate fraction of Andrographis paniculata Nees increases cytotoxic effect of 5-fluorouracil on human cancer cell lines. Int J Pharm Pharm Sci 2014;6(5):1-5.

13. Farmani F, Moein M, Amanzadeh A, Kandelous HM, Ehsanpour Z, Salimi M. Antiproliferative evaluation and apoptosis induction in MCF-7 cells by Ziziphus spina christi leaf extracts. Asian Pac J Cancer Prev 2016;17(1):315-21.

14. Thongnest $\mathrm{S}$, Chawengrum $\mathrm{P}$, Keeratichamroen $\mathrm{S}$, Lirdprapamongkol K, Eurtivong C, Boonsombat J, et al. Vernodalidimer L, a sesquiterpene lactone dimer from Vernonia extensa and anti-tumor effects of vernodalin, vernolepin and vernolide on HepG2 liver cancer cells. Bioorg Chem 2019;92:1-10.

15. Moldoveanu SC, David V. Mobile phases and their properties. Essentials in Modern HPLC Separations 2013:363-447.

16. Abarca-Vargas R, Petricevich VL. Comparison of Different Extraction Methods for the Phenolic Compounds Recovery with the Antioxidant Activity of Bougainvillea x buttiana. Curr Anal Chem 2020;16(6):778-87.

17. Grachev V, Magrath D, Griffiths E, Petricciani JC. WHO requirements for the use of animal cells as in vitro substrates for the production of biologicals (requirements for biological substances No. 50). Biologicals 1998;26(3):175-93.

18. Almeida JL, Hill CR, Cole KD. Mouse cell line authentication. Cytotechnology 2014;66(1):133-47.

19. Sriwiriyajan S, Ninpesh $T$, Sukpondma $Y$, Nasomyon $T$, Graidist P. Cytotoxicity screening of plants of genus Piper in breast cancer cell lines. Trop J Pharm Res 2014;13(6):921-8.

20. Tedasen A, Khoka A, Madla S, Sriwiriyajan S, Graidist P. Anticancer effects of piperine-free Piper nigrum extract on cholangiocarcinoma cell lines. Pharmacogn Mag 2020;16(68):28.

21. Matsuda H, Ninomiya K, Morikawa T, Yasuda D, Yamaguchi I, Yoshikawa M. Hepatoprotective amide constituents from the fruit of Piper chaba: Structural requirements, mode of action and new amides. Bioorg Med Chem 2009;17(20):7313-23.

22. Matsuda H, Ninomiya K, Morikawa T, Yasuda D, Yamaguchi I, Yoshikawa M. Protective effects of amide constituents from the fruit of Piper chaba on d-galactosamine/TNF- $\alpha$-induced cell death in mouse hepatocytes. Bioorg Med Chem Lett 2008;18(6):2038-42.

23. Eastman A. Improving anticancer drug development begins with cell culture: misinformation perpetrated by the misuse of cytotoxicity assays. Oncotarget 2017;8(5):8854-66.

24. Singh S, Mehta A, Baweja S, Ahirwal L, Mehta P. Anticancer activity of Andrographis paniculata and Silybum marianum on five human cancer cell lines. J Pharmacol Toxicol 2013;8(1):42-8.

25. Madlum KN, Galib RA, Ghazi FM, Ali ZH. The effects of Zizyphus stem bark and termite shelter tubes on HeLa cell growth. Res J Pharm BiolChem Sci 2015;6(6):620-6.

26. Seong J, Oyong GG, Cabrera EC. Synsepalum dulcificum extracts exhibit cytotoxic activity on human colorectal cancer cells and upregulate c-fos and c-jun early apoptotic gene expression. Asian Pac J Trop Biomed 2018;8(3):173-8.

27. Sriwiriyajan S, Tedasen A, Lailerd N, Boonyaphiphat $\mathrm{P}$, Nitiruangjarat A, Deng $\mathrm{Y}$, et al. Anticancer and cancer prevention effects of piperine free Piper nigrum extract on $\mathrm{N}$-nitrosomethylurea-induced mammary tumorigenesis in rats. Cancer Prev Res 2016;9(1):74-82.

28. Chou T-C, Martin N. A computer program for quantitation of synergism and antagonism in drug combinations and the determination of $\mathrm{IC}_{50}$ and $\mathrm{ED}_{50}$ and $\mathrm{LD}_{50}$ values. Paramus, New Jersey: ComboSyn; 2005.

29. Chou TC, Talalay P. Analysis of combined drug effects: a new look at a very old problem. Trends Pharmacol Sci 1983;4:4504.

30. Chou TC. Theoretical basis, experimental design and computerized simulation of synergism and antagonism in drug combination studies. Pharmacol Rev 2006;58(3):621-81.

31. Santos-Sanchez NF, Salas-Coronado R, Villanueva-Canongo C, Hernandez-Carlos B. Antioxidant compounds and their antioxidant mechanism. London, UK: IntechOpen; 2019. p. $1-28$.

32. Widyawati PS, Budianta TD, Kusuma FA, Wijaya EL. Difference of solvent polarity to phytochemical content and antioxidant activity of Pluchea indicia less leaves extracts. Int J Pharmacogn Phytochem 2014;6(4):850-5.

33. Tan MC, Oyong GG, Shen CC, Ragasa CY. Cytotoxic activities of the dichloromethane extract from Andrographis paniculata (Burm. f.) nees. J Nat Sci Biol Med 2018;9(2):201-6.

34. Allison SD, Randolph TW, Manning MC, Middleton K, Davis A, Carpenter JF. Effects of drying methods and additives on structure and function of actin: mechanisms of dehydrationinduced damage and its inhibition. Arch Biochem Biophys 
1998;358(1):171-81.

35. Koch A, Tamez P, Pezzuto J, Soejarto D. Evaluation of plants used for antimalarial treatment by the Maasai of Kenya. J Ethnopharmacol 2005;101(1):95-9.

36. Ravi L, Krishnan K. Cytotoxic potential of N-hexadecanoic acid extracted from Kigelia pinnata leaves. Asian J Cell Biol 2017;12(1):20-7.

37. Eswaraiah G, Peele KA, Krupanidhi S, Kumar RB, Venkateswarulu TC. Identification of bioactive compounds in leaf extract of Avicennia alba by GC-MS analysis and evaluation of its in vitro anticancer potential against MCF7 and HeLa cell lines. J King Saud Univ Sci 2020;32(1):740-4.

38. Sakthivel R, Malar DS, Devi KP. Phytol shows anti angiogenic activity and induces apoptosis in A549 cells by depolarizing the mitochondrial membrane potential. Biomed Pharmacother 2018;105:742-52.

39. $\mathrm{Lu} \mathrm{X}, \mathrm{Yu} \mathrm{H}, \mathrm{Ma} \mathrm{Q}$, Shen $\mathrm{S}$, Das UN. Linoleic acid suppresses colorectal cancer cell growth by inducing oxidant stress and mitochondrial dysfunction. Lipids Health Dis 2010;9(1):106.

40. Kim SJ, Chung WS, Kim SS, Ko SG, Um JY. Antiinflammatory effect of Oldenlandia diffusa and its constituent, hentriacontane, through suppression of caspase-1 activation in mouse peritoneal macrophages. Phytother Res 2011;25(10):1537-46.

41. Farid MM, Hussein SR, Ibrahim LF, El Desouky MA, Elsayed AM, El Oqlah AA, et al. Cytotoxic activity and phytochemical analysis of Arum palaestinum Boiss. Asian Pac J Trop Biomed 2015;5(11):944-7.

42. Alkhalaf MI, Alansari WS, Ibrahim EA, ELhalwagy ME. Anti-oxidant, anti-inflammatory and anti-cancer activities of avocado (Persea americana) fruit and seed extract. J King Saud Univ Sci 2019;31(4):1358-62.

43. Want EJ, Cravatt BF, Siuzdak G. The expanding role of mass spectrometry in metabolite profiling and characterization. Chembiochem 2005;6(11):1941-51.

44. Jain PK, Soni A, Jain P, Bhawsar J. Phytochemical analysis of Mentha spicata plant extract using UV-VIS, FTIR and GC/MS technique. J Chem Pharm Res 2016;8(2):1-6.

45. Wulandari L, Retnaningtyas Y, Lukman H. Analysis of flavonoid in medicinal plant extracts using infrared spectroscopy and chemometrics. J Anal Methods Chem 2016;2016.

46. Irawan C, Rochaeni H, Sulistiawaty L, Roziafanto AN. Phytochemical Screening, LC-MS Studies and Antidiabetic Potential of Methanol Extracts of Seed Shells of Archidendron bubalinum (Jack) IC Nielson (Julang Jaling) from Lampung, Indonesia. Pharmacogn J 2018;10(6):S77-82.

47. Baldissera MD, Souza CF, Grando TH, Stefani LM, Monteiro SG. $\beta$-caryophyllene reduces atherogenic index and coronary risk index in hypercholesterolemic rats: The involvement of cardiac oxidative damage. Chem Biol Interact 2017;270:9-14.

48. Kamikubo R, Kai K, Tsuji-Naito K, Akagawa M. $\beta$ Caryophyllene attenuates palmitate-induced lipid accumulation through AMPK signaling by activating CB2 receptor in human HepG2 hepatocytes. Mol Nutr Food Res 2016;60(10):2228-42.

49. Sriwiriyajan S, Sukpondma Y, Srisawat T, Madla S, Graidist P. (-)-Kusunokinin and piperloguminine from Piper nigrum: An alternative option to treat breast cancer. Biomed Pharmacother 2017;92:732-43.

50. Skok Z, Zidar N, Kikelj D, Ilas J. Dual inhibitors of human DNA topoisomerase II and other cancer-related targets. J med chem 2019;63(3):884-904.

51. Sohretoglu D, Barut B, Sari S, Ozel A, Arroo R. In vitro and in silico assessment of DNA interaction, topoisomerase I and II inhibition properties of chrysosplenetin. Int J Biol Macromol 2020;163:1053-9.

52. Stepanek O, Brdicka T, Angelisova P, Horvath O, Spicka J, Stockbauer $\mathrm{P}$, et al. Interaction of late apoptotic and necrotic cells with vitronectin. PLoS One 2011;6(5):e19243.

53. Rezadoost MH, Kumleh HH, Ghasempour A. Cytotoxicity and apoptosis induction in breast cancer, skin cancer and glioblastoma cells by plant extracts. Mol Biol Rep 2019;46(5):5131-42.

54. Li C, Jing H, Ma G, Liang P. Allicin induces apoptosis through activation of both intrinsic and extrinsic pathways in glioma cells. Mol Med Rep 2018;17(4):5976-81.

55. Parrish AB, Freel CD, Kornbluth S. Cellular mechanisms controlling caspase activation and function. Cold Spring Harb Perspect Biol 2013;5(6):a008672.

56. Ulloth JE, Casiano CA, De Leon M. Palmitic and stearic fatty acids induce caspase-dependent and-independent cell death in nerve growth factor differentiated PC12 cells. J Neurochem 2003;84(4):655-68.

57. Kim YS, Li XF, Kang KH, Ryu B, Kim SK. Stigmasterol isolated from marine microalgae Navicula incerta induces apoptosis in human hepatoma HepG2 cells. BMB Rep 2014;47(8):433-8. 